3

\title{
Teleconnection stationarity, variability and trends of the Southern Annular Mode (SAM) during the last millennium
}

Christoph Dätwyler ${ }^{1}$, Raphael Neukom ${ }^{1}$, Nerilie Abram² ${ }^{2}$ Ailie Gallant ${ }^{3}$, Martin Grosjean ${ }^{1}$, Martín Jacques-Coper ${ }^{4}$, David Karoly ${ }^{5} \&$ Ricardo Villalba ${ }^{6}$

${ }^{1}$ Institute of Geography \& Oeschger Centre for Climate Change Research, University of Bern, 3012 Bern, Switzerland

${ }^{2}$ Research School of Earth Sciences and ARC Centre of Excellence for Climate System Science, Australian National University

${ }^{3}$ School of Earth, Atmosphere and Environment, Monash University, Victoria 3800, Australia

${ }^{4}$ Departamento de Geofísica, Universidad de Concepción, Concepción, Chile

${ }^{5}$ School of Earth Sciences and ARC Centre of Excellence for Climate System Science, University of Melbourne, Victoria 3010, Australia

${ }^{6}$ Instituto Argentino de Nivología, Glaciología y Ciencias Ambientales (IANIGLA), CCT CONICET, 5500 Mendoza, Argentina

Corresponding author: Christoph Dätwyler, christoph.daetwyler@giub.unibe.ch, +41 316315091

ORCID: Christoph Dätwyler 0000-0002-9923-4311

Raphael Neukom 0000-0001-9392-0997

Ricardo Villalba 0000-0001-8183-0310

\section{Acknowledgement and funding}

Researchers from the PAGES2k consortium are acknowledged for providing access to data and metadata information. We thank Michael N. Evans for discussions. This study was supported by the Swiss National Science Foundation (SNF) Ambizione grant PZOOP2_154802. RN, MG, and CD designed the study; RN and CD led the writing and conducted the data analysis. All authors jointly discussed and contributed to the writing. 
The Southern Annular Mode (SAM) is the leading mode of atmospheric interannual variability in the Southern Hemisphere (SH) extra-tropics. Here, we assess the stationarity of SAM spatial correlations with instrumental and paleoclimate proxy data for the past millennium. The instrumental period shows that temporal non-stationarities in SAM teleconnections are not consistent across the SH land areas. This suggests that the influence of the SAM index is modulated by regional effects. However, within key-regions with good proxy data coverage (South America, Tasmania, New Zealand), teleconnections are mostly stationary over the instrumental period. Using different stationarity criteria for proxy record selection, we provide new austral summer and annual mean SAM index reconstructions over the last millennium. Our summer SAM reconstructions are very robust to changes in proxy record selection and the selection of the calibration period, particularly on the multi-decadal timescale. In contrast, the weaker performance and lower agreement in the annual mean SAM reconstructions point towards changing teleconnection patterns that may be particularly important outside the summer months. The summer SAM reconstructions show no significant relationship to solar, greenhouse gas and volcanic forcing, with the exception of an extremely strong negative anomaly following the AD 1257 Samalas eruption. Our results clearly portend that the temporal stationarity of the proxy-climate relationships should be taken into account in the design of comprehensive regional and hemispherical climate reconstructions. Furthermore, reconstructed pre-industrial summer SAM trends are very similar to trends obtained by model control simulations. We find that recent trends in the summer SAM lie outside the 5-95\% range of pre-industrial natural variability.

Keywords: Climate change, Climate reconstruction, Paleoclimate, Southern Hemisphere, Holocene 


\section{Introduction}

The Southern Annular Mode (SAM), also known as Antarctic Oscillation (AAO) or High Latitude Mode (HLM, Lorenz and Hartmann 2001), is the leading mode of atmospheric variability in the Southern Hemisphere (SH) extra-tropics (Silvestri and Vera 2009; Manatsa et al. 2015, 2015). The SAM is usually defined as the first principal component of climate variability in the $\mathrm{SH}$ using a parameter such as the geopotential height (Thompson and Wallace 2000). Alternatively, the SAM can be described by the normalised zonal mean sea level pressure difference between $40^{\circ}$ and $65^{\circ} \mathrm{S}$ (Gong and Wang 1999). The SAM describes the strength and north-south movement of the largely zonally symmetric westerly wind belt, which results in anti-correlated centres of zonal wind anomalies at around $40^{\circ}$ and $60^{\circ} \mathrm{S}$ (Kidson 1988). The zonal symmetry (also referred to as the annular structure) arises from the ocean dominated SH and its orography, with highly reduced continental effects compared to the Northern Hemisphere.

The main driving mechanism behind changes in the strength and position of the $\mathrm{SH}$ westerlies is the non-uniform heating of the Earth's surface. This difference in the radiation budget leads to a large temperature and pressure gradient between tropical and polar regions, resulting in geostrophic westerly winds at mid-latitudes (Bromwich and Parish 1998). A positive SAM index is associated with negative high-latitude and positive mid-latitude pressure anomalies. This leads to a shift of the storm tracks towards the South Pole and to a strengthening of the westerly winds circling Antarctica (Thompson and Wallace 2000; Jones et al. 2009b). Conversely, during negative SAM phases the position of the storm tracks is moved towards the Equator due to positive high-latitude and negative mid-latitude pressure anomalies, resulting in weaker circumpolar westerlies.

Due to its hemispheric extent, the consequences of changes in the SAM are far-ranging. Sinclair et al. (1997) report effects on cyclone and anticyclone activity between middle to high latitudes. Increased westerlies around $55^{\circ}-56^{\circ} \mathrm{S}$ are found to raise the number of cyclones in circumpolar regions and lower the number in the mid-latitudes and vice versa. Influences on ocean and sea ice variability were studied by, for example, Watterson (2000), Lefebvre (2004), Liu et al. (2004) or Gupta and England (2006). 
Possible mixing with other decadal modes of SH variability such as the El-Niño Southern-Oscillation (ENSO) has been analysed by Pittock (1984), Karoly et al. (1996) or Fogt et al. (2011). Impacts on regional rainfall and temperature all over the SH have been discussed by numerous authors, including Gillett et al. (2006) who used station observations, and Gupta and England (2006) who used reanalysis and model data. The positive phase of the SAM is associated with cooling over most of Antarctica and large parts of Australia (Thompson and Solomon 2002; Gillett et al. 2006; Gupta and England 2006), contrasting with warming over the Antarctic Peninsula, the southern tip of South America, Tasmania and New Zealand (Thompson and Solomon 2002; Gillett et al. 2006; Gupta and England 2006). Extreme states of the SAM are equally linked to changes in SH hydroclimate. These changes manifest themselves as anomalously dry conditions in austral winter over western South Africa, southern Australia and southwest Western Australia (Reason and Rouault 2005; Cai and Cowan 2006; Hendon et al. 2007) during SAM positive phases, whereas south-eastern South America in austral winter and the southern east coast of Australia in austral summer show anomalously wet responses (Silvestri and Vera 2003; Hendon et al. 2007). Likewise, a decrease in annual precipitation over southern South America, New Zealand and Tasmania is linked to positive SAM anomalies, contrasting increased precipitation in South Africa and over much of Australia (Gillett et al. 2006).

Through large-scale modes of climate variability such as the SAM, very distant geographic locations become climatically connected. These spatial relationships between distant geographic locations are referred to as teleconnections. In the context of comprehensive large-scale reconstructions of climate variability and modes, teleconnection patterns are fundamentally important because one of the key assumptions is that teleconnections have remained constant through time.

Reconstructions of regional SH temperature (Neukom et al. 2011; PAGES 2k Consortium 2013; Gergis et al. 2016; Stenni et al. 2017), hydroclimate (Neukom et al. 2010; Gergis et al. 2012; Palmer et al. 2015; Nash et al. 2016) and the SAM (Villalba et al. 2012, hereafter V12; Abram et al. 2014, hereafter A14) over the last centuries show remarkable differences. Besides geographic location and seasonality of the reconstructions, considerable variability in the strength of teleconnections may lead to those 
disagreements. Furthermore, factors such as tropical variability (e.g. ENSO), changing greenhouse gas (GHG) concentrations or ozone depletion modulate the varying influences of the SAM on regional climate across the SH continents, and modify its temporal stationarity (Thompson and Wallace 2000; Thompson et al. 2011; Brönnimann et al. 2017). Although changing teleconnections can have severe implications for future climate projections, systematic analyses on multi-decadal and longer time scales are largely missing. In addition, non-stationary teleconnections are problematic when interpreting paleoclimate data, since most spatially explicit reconstruction techniques (e.g. principal component regression (PCR), regularised expectation maximisation (RegEM) or composite-plus-scaling (CPS)) are not able to capture teleconnections that were different from those that prevailed in the instrumental calibration period.

Knowledge of long-term variability in the SAM is important to assess the influence of forcings (e.g. ozone, GHG, solar and volcanic) and to put recent trends into a long-term context. However, the influence of external forcings on the high-latitude SH climate is largely unknown, e.g. there is no consensus about response of the SAM to volcanic forcing (McGraw et al. 2016). This lack of knowledge is caused by missing paleoclimate and high-quality instrumental data combined with limited capability of model simulations to simulate climate variability in these areas. Nevertheless, there is evidence that recent positive trends in the SAM have been pushed out of their range of natural variability due to stratospheric ozone depletion and anthropogenic GHG emissions (Sexton 2001; Thompson and Solomon 2002; Arblaster and Meehl 2006; Gillett and Fyfe 2013; Bindoff et al. 2014). To our knowledge, this important finding has not yet been confirmed by empirical proxy-based paleoclimate reconstructions.

Currently, SAM reconstructions are available for austral summer (DJF) back to AD 1409 (V12) and annual means (J-D) back to AD 1000 (A14). While both reconstructions show more negative SAM index values over the past centuries with a minimum in the $15^{\text {th }}$ century, there are considerable differences between the two reconstructions on inter-annual to multi-decadal time-scales. These differences may be due to a significant but not very strong relationships between the annual and DJF SAM ( $r=0.56$ over 
1958-2005 for the Fogt SAM index). Alternatively, they may arise from the use of proxy records from different regions that are affected by teleconnection changes.

Consequently, the goals of our study are,

- to assess the sensitivity of millennial-long SAM reconstructions to different proxy selection regimes using various stationarity criteria

- to analyse the responses of the SAM to external forcings

- to quantify and assess recent trends in the SAM in a long-term context

To achieve these goals, we first analyse the correlation of $\mathrm{SH}$ regional temperature and precipitation with the SAM during the instrumental period. Correlations are assessed for their stationarity using a range of different criteria. We then use the same stationarity criteria to select proxy records for DJF and annual SAM reconstructions using a greatly expanded database of temperature-sensitive proxy records (PAGES 2k Consortium 2017). The resulting SAM index reconstructions are compared to previous reconstructions (A14 and V12) which were generated using conventional correlation-based selection of proxy records (Mann et al. 2008; Jones et al. 2009a). We finally assess the response of the SAM to external forcing (ozone, GHG and volcanic) and use our new reconstructions to analyse recent summer SAM trends in a millennium-long perspective.

\section{Data and Methods}

\subsection{Instrumental Data}

For temperature, we used the gridded HadCRUT4.3 temperature product covering 1850-2014 (Morice et al. 2012). Missing values were filled using GraphEM (PAGES 2k Consortium 2017). For precipitation, we used the CRU TS 3.23 precipitation data (Harris et al. 2014). Both datasets were interpolated to a $1^{\circ} \times 1^{\circ}$ grid with CDO (Climate Data Operators) and converted to anomalies with respect to 1961-1990 means. The precipitation data cover land areas only and do not extend to Antarctica, whereas the temperature data cover the whole $\mathrm{SH}$, including Antarctica. Note that for many regions in the $\mathrm{SH}$, 
particularly at high latitudes, instrumental data coverage is very poor prior to ca. 1960, thus posing a caveat to the interpretation of gridded climate products in the first half of the $20^{\text {th }}$ century. A variety of SAM indices is available from the literature. For a comparison of the different SAM indices and further information on them, we refer to Ho et al. (2012). For our studies we used the Fogt (Fogt et al. 2009; Jones et al. 2009b) and Marshall SAM indices (Marshall 2003). The Fogt SAM index is accessible through http://polarmet.osu.edu/ACD/sam/sam_recon.html. It is available from 1866 to 2005 (DJF), 1865 to 2005 (MAM) and 1905 to 2005 (JJA and SON). The Fogt SAM index was reconstructed using principal component regression of observed station pressure data across the $\mathrm{SH}$, then calibrated to the Marshall SAM index. As annual means, we used the average of the four seasonal reconstructions. Hence an annual Fogt SAM value runs from December to November. The Marshall SAM index is based on station mean sea level pressure (MSLP) measurements between $40^{\circ} \mathrm{S}$ and $65^{\circ} \mathrm{S}$ from 1957 until present and is still being updated on a monthly basis. The data can be downloaded at

\section{https://legacy.bas.ac.uk/met/gima/sam.html.}

\subsection{Proxy data}

Our proxy network consists of mainly tree-ring and ice core proxy records from western South America, Patagonia, Australia, New Zealand and Antarctica. It uses the global PAGES2k collection of temperature sensitive proxy records (PAGES 2k Consortium 2017, details see supplementary material (SM) section 8), the SH temperature proxy network of Neukom et al. (2014), the recent compilation of Antarctic ice core isotope data from Stenni et al. (2017) and the proxy databases used for the V12 and A14 studies. Details on all proxy records are given in SM Table S4 and S5. Identical records existing in multiple data products were removed manually. Some tree-ring composite chronologies that share a certain fraction of common input data were kept in the final proxy matrix, which leads to some redundancy in a small number of records (details in SM section 8.1). We used a long (1905-2005) and a short (1957-1995, respectively 1958-1995 for DJF since there is no December value in 1956 for the Marshall SAM index) calibration interval and only used proxy records with $70(30)$ or more annual data points in these 
periods. In the calibration period, remaining missing values in the proxy matrix were infilled with DINEOF (Taylor et al. 2013) which interpolates data using empirical orthogonal functions. In total, our proxy matrix includes 326 records; all data are available at the NOAA paleoclimate database [link]. The spatial distribution and the numbers for each archive type is depicted in Fig. 1.

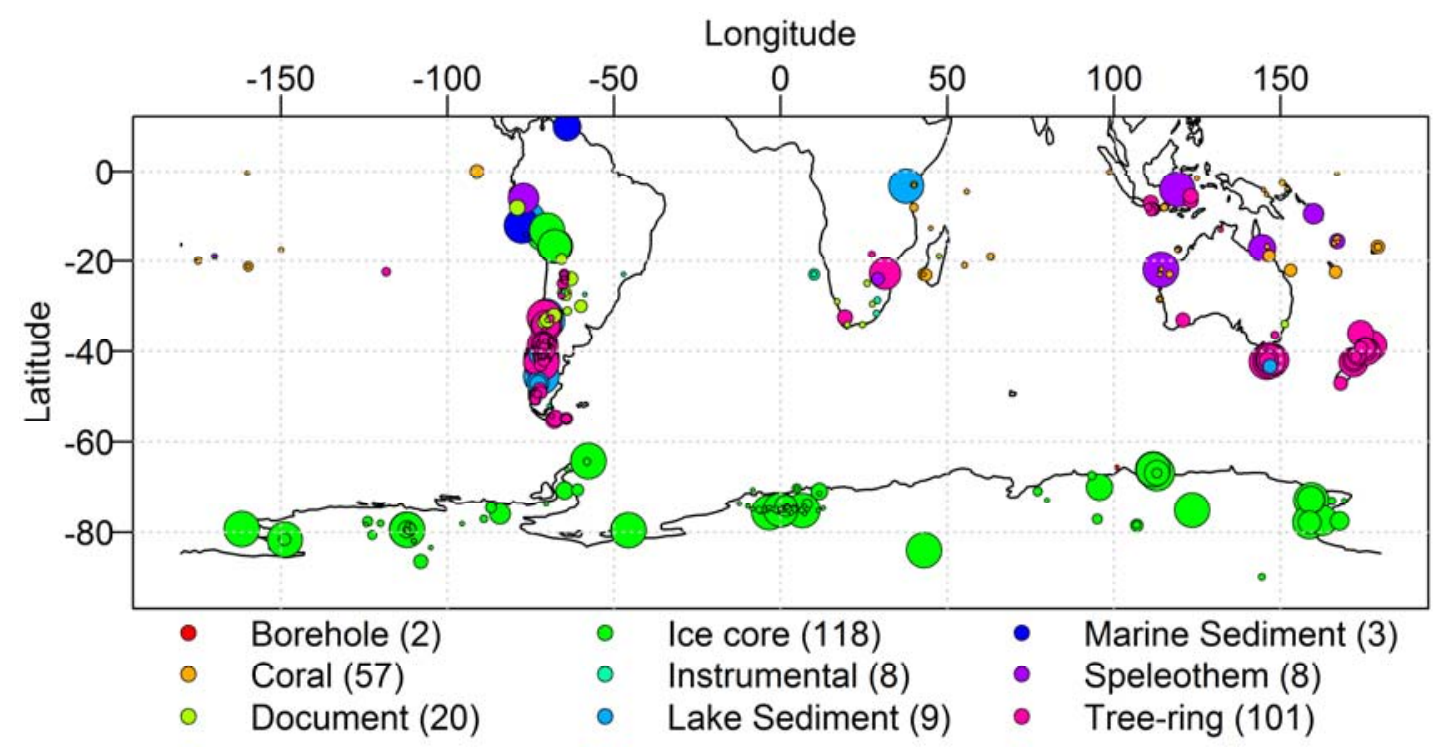

Fig. 1 Distribution of all proxy records (326 in total) for the long calibration experiments. Proxy records are coloured by archive type. The size of the circles corresponds to the record length (between 140 and 1011 years). Numbers in parenthesis indicate the number of records for the respective archive type. The analogue figure for the short calibration experiments is shown in SM Fig. S2

\subsection{Methods}

\subsubsection{Stationarity tests}

We used four different methods (Geshunov Test, Gallant Test, Akaike Information Criterion Test and Sign Test; details below) to assess the stationarity between regional climate (observations and proxy records) and the SAM index. Three of the four tests are based on running correlations. For stationarity tests over the period 1905-2005 (long calibration) we used a 31-year correlation window, whereas for the shorter time span 1958-1995 (short calibration) the window width was 11 years.

The Gershunov Test (Gershunov et al. 2001) checks whether the variance of a running correlation between two input time series is larger than could be expected by chance, based on comparison with 
white noise time series. Running correlations of 500 pairs of white noise time series with the same overall correlation as the input time series are generated. The range of standard deviations of these running correlations is used to obtain a p-value. The $p$-value reflects the percentage of cases in which the standard deviations of these running correlations are larger than the standard deviation of the running correlation of the two input time series. Thus, a p-value smaller than 0.05 means that the input running correlation time series can be considered significantly more variable than can be expected from pairs of Gaussian noise processes. Here, we consider a p-value smaller (greater) than 0.05 as a non-stationary (stationary) running correlation.

The Gallant Test (van Oldenborgh 2005; Sterl et al. 2007; Gallant et al. 2013) provides a confidence interval wherein the running correlations are expected to reside, if the relationship (between SAM and climate or proxy data) was only influenced by local climate or proxy noise. This is performed by creating a multitude of stochastic climate/proxy series based on the regression relationship between the climate/proxy data and the SAM. These stochastic time series are then used to calculate the confidence interval. If the running correlation to be tested falls outside the confidence interval at least once during the period analysed, the relationship is considered non-stationary.

With the Akaike Information Criterion (AIC) Test (Petris and Petrone 2011) we compared the AIC of a constant coefficient model to the AIC of a model with a time-varying coefficient. For two normalised time series $x=\left\{x_{1}, x_{2}, \ldots, x_{n}\right\}$ and $y=\left\{y_{1}, y_{2}, \ldots, y_{n}\right\}$ of length $n$, the constant coefficient model is defined as follows (Tusell 2011)

$$
y_{t}=\lambda x_{t}+\varepsilon_{t}, \quad \text { where } \varepsilon_{t} \sim \mathcal{N}\left(0, \sigma_{\varepsilon}^{2}\right),
$$

whereas the state space model with the time varying coefficient is defined as

$$
\begin{aligned}
& y_{t}=\lambda_{t} x_{t}+\varepsilon_{t}, \quad \text { where } \varepsilon_{t} \sim \mathcal{N}\left(0, \sigma_{\varepsilon}^{2}\right) \\
& \lambda_{t}=\lambda_{t}+\zeta_{t-1}, \quad \text { where } \zeta_{t} \sim \mathcal{N}\left(0, \sigma_{\zeta}^{2}\right) .
\end{aligned}
$$

The parameter values of the models maximising the likelihood function $\hat{L}$ are estimated via maximum likelihood estimation. Then the AIC is calculated as $A I C=2 k-2 \ln \hat{L}$, where $k$ is the number of estimated parameters. If the difference between the AIC of the linear model allowing its slope 
parameter to vary over time $\left(\mathrm{AIC}_{\mathrm{t}}\right)$ and the constant coefficient linear model $\left(\mathrm{AIC}_{\mathrm{c}}\right)$ is smaller than zero $\left(A I C_{t}-A I C_{c}<0\right)$, we call the relationship non-stationary.

The Sign Test assesses if a running correlation time series changes its sign at least once either from positive to negative or negative to positive. If there is a change (no change) in the sign, then we call the running correlation non-stationary (stationary). This is a rather simple test, not providing a formal p-value and, to our knowledge, not commonly used in literature. Therefore, we use it as an independent comparison of the results based on the three other tests.

\subsubsection{Proxy selection}

We performed SAM reconstructions with varying sets of proxy records. The proxy selection process was based on five different selection regimes as defined in the following:

The Correlation Selection criterion (henceforth Cor selection; e.g. Mann et al. 2008; Jones et al. 2009a) selects the proxy records based on their correlation with the target (SAM). Only records with a detrended correlation significant at the 0.05 level over the calibration period are used. Lag one autocorrelation was taken into account when testing for significance of a correlation (Santer et al. 2000), and all data were detrended over the respective time period. This yields conservative estimates of significance and avoids spurious correlations from common trends. For a discussion of using detrended versus non-detrended data for proxy selection see (von Storch et al. 2004; Bürger and Cubasch 2005; Wahl et al. 2006; Wahl and Ammann 2007; Gergis et al. 2016).

The Correlation Plus Stationarity criterion (henceforth Cor \& Stat selection) selects proxy records if they fulfil the Cor selection criterion and, in addition, show a stationary proxy-SAM relationship in the calibration period according to all of the three stationarity tests (Gershunov, Gallant and AIC Tests). The Sign Test criterion (henceforth Sign Test selection) selects proxy records passing the Sign Test as stationary; a significant correlation with the target (SAM) is not required. 
only the original V12 or A14 records. We replicate their reconstructions using our CPS reconstruction method (see section 2.3.3 below) in order to reach consistency with our other experiments. Our replication of the V12 reconstruction is very similar ( $r=0.99, p<<0.01$, SM Fig. S17) to the original V12 reconstruction although we use a different reconstruction technique (but the same proxy data). Also, our replication of the A14 reconstruction is almost identical to the original A14 reconstruction ( $r=0.98$, $\mathrm{p}<<0.01$, SM Fig. S18).

The full proxy network (henceforth All Proxies, Fig. 1) uses all proxy records in our network without any screening.

\subsubsection{Reconstructions}

All the different proxy selection variants (Cor, Cor \& Stat, Sign Test, Abram, Villalba and All Proxies) were treated with the same reconstruction method. We refer to the resulting reconstructions as Cor, Cor \& Stat, Sign Test, Abram, Villalba and All Proxies reconstruction. We used the nested CPS method (Jones et al. 2009a), implemented as in Gergis et al. (2016), to perform DJF and annual SAM reconstructions. This method generates an ensemble of 1000 reconstructions based on re-sampling from reconstruction parameters (proxy network, proxy weights) and calibration residuals. In order to assess the robustness of the reconstructions with respect to the length of the calibration period, they were run using a long (1905-2005) and short (1957/58-1995) calibration interval. To generate the composites, proxy records were weighted by their non-detrended correlation with the reconstruction target over the calibration period (Jones et al. 2009a; A14; Neukom et al. 2014; Gergis et al. 2016). For calibration of our SAM reconstructions we used the Marshall summer (DJF) SAM index (consistent with the reconstruction of V12) and the Marshall annual (Jan-Dec) SAM index (consistent with the A14 reconstruction). The long calibration reconstructions use the Fogt SAM index as target, since the Marshall SAM index only dates back to 1957.

Multiple skill metrics were computed to assess the performance of the reconstructions. They include the commonly used reduction of error (RE), $\mathrm{R}^{2}$ and root mean square error (RMSE) skill metrics (Cook 
et al. 1994). They were calculated over the calibration periods to be consistent with results from V12 and A14 and because the short temporal coverage of the Marshall SAM index does not allow a reasonable splitting of the data into separate calibration and validation periods. For the long calibration experiments, we sub-sampled the calibration period for each ensemble member using between 55 and 76 years for calibration (validation between 25 and 46 years; Gergis et al. 2016). For the validation statistics (SM Table S3) we used the ensemble median of only those years that were used for validation for each ensemble member (details see Neukom et al. 2014).

As an additional measure to validate the stationarity of a reconstruction, we calculated the number of stationarity criteria (maximum four) which were fulfilled over the period 1905-1957 using 31-year moving windows. Moreover, we computed the ratio of standard deviations between 1905-1956/57 and 1957/58-1995 in each reconstruction divided by the same standard deviation ratio as in the target SAM data. This quotient provides an estimate of the variance losses in the reconstruction experiments. Such variance losses are an additional indicative of a reduced quality of the reconstruction.

Stationarity tests and standard deviation ratios for the long calibration experiments are based on proxy records selection over the 1905-2005 interval but calibrated only over 1957/58-1995.

\subsubsection{External forcing}

To evaluate, whether large volcanic eruptions cause an increase or decrease in the SAM index, we performed an epoch analysis (Haurwitz and Brier 1981; Bradley et al. 1987; Sear et al. 1987; McGraw et al. 2016). We used the eVolv2k volcanic forcing dataset based on Sigl et al. (2015a) and selected all eruptions with an aerosol optical depth (AOD) larger than 15 . This yielded 13 eruptions within the last millennium. For each event, the reconstructed SAM index between 5 years prior to the eruption (year $-5)$ and 9 years after the eruption (year +9$)$ was selected. These 14-year time series were then linearly detrended and centred relative to the years -5 to -1 . To test whether eruptions cause a significant increase or decrease in the SAM index, we repeated the above steps (detrending and centering) for all (overlapping) 14-year periods of the last millennium and calculate their 5-95\% range. Since we tested 
13 eruptions for a non-significant response, we applied the Bonferroni correction (Holm 1979) to this range, in order to get a very conservative familywise $5-95 \%$ confidence interval. That is, the familywise 5-95\% confidence interval corresponds to a $0.385-99.615 \%$ confidence interval for a single test.

The evaluation of a possible relationship between the SAM index and $\mathrm{CO}_{2}$ or solar forcing was performed using 101-year and 71-year running correlations over the years AD 1000 to 2000. For solar forcing, we used the SATIRE-H (Spectral And Total Irradiance Reconstructions - Holocene) data, which uses isotope ${ }^{14} \mathrm{C}$ in tree-rings as input (Vieira et al. 2011). The $\mathrm{CO}_{2}$ data are from Meinshausen et al. (2017).

\subsubsection{Trend analysis}

We calculated 60-year trends in our reconstructions for the pre-industrial (prior to 1850) and industrial (after 1850 to present) period and compared them to the range of trends in the Fifth Coupled Model Intercomparison Project (CMIP5) control simulations as reported in Bindoff et al. (2014). This allows us to assess if recent trends in the SAM are outside the range expected from natural variability and to check how well models capture natural pre-industrial SAM variability. For additional verification of the results we calculated two SAM indices using the HadSLP2r (Allan and Ansell 2006) (with variance adjustment from 2005 to 2012) and 20 ${ }^{\text {th }}$ Century Reanalysis (20CR; Compo et al. 2011) data sets. Based on the Gong and Wang (1999) definition of the SAM, these indices were calculated as the difference between zonal mean SLP (in $\mathrm{hPa}$ ) at $40^{\circ} \mathrm{S}$ and $65^{\circ} \mathrm{S}$. In order to make the magnitudes of simulated and observed trends comparable, no normalisation was used. As in Bindoff et al. (2014), we calculated the 60-year trend for the HadSLP2r and 20CR-based SAM indices over the period 1952-2011.

The standard deviation of the Fogt SAM index and our reconstruction was adjusted to have the same standard deviation as the HadSLP2r SAM index over 1905-2005, whereas the standard deviation of the Marshall SAM index was scaled to the period 1958-2012 (maximal overlap).

To verify and investigate the robustness our results, we recalculated our reconstructions by weighting the proxy records by their detrended correlation with the target over the calibration period. This 
ensures, that any recent trend we obtain which is significantly outside the range of pre-industrial SAM

331 variability, is not an artefact of giving too much weight to proxies in the reconstruction with a common

332 trend with the target SAM index over in the $20^{\text {th }}$ century. Additionally, 100 noise-proxy reconstructions

333 were generated (each of which resulting from an ensemble of 100 members). Noise proxies were

334 generated as inWahl and Smerdon (2012): For each proxy record, a random noise time series with the

335 same autocorrelation structure and time period covered was generated. 100 such proxy matrices were

336 created and then subjected to the CPS reconstruction method, to identify whether the strong trend

337 over the calibration period may result by chance as an artefact of the reconstruction method. 


\section{Results}

\subsection{Stationarity between SH climate and the SAM over the instrumental period}

342 Fig. 2 shows the strength of the stationarity between climate and SAM during the instrumental period

343 (1905-2005) according to the four stationarity tests applied (Gershunov, Gallant, AIC und Sign Test;

white color: no test fulfilled, light green color: all four tests fulfilled). The spatial pattern of stationarity

differs between temperature and precipitation, and between seasons (DJF or annual). The
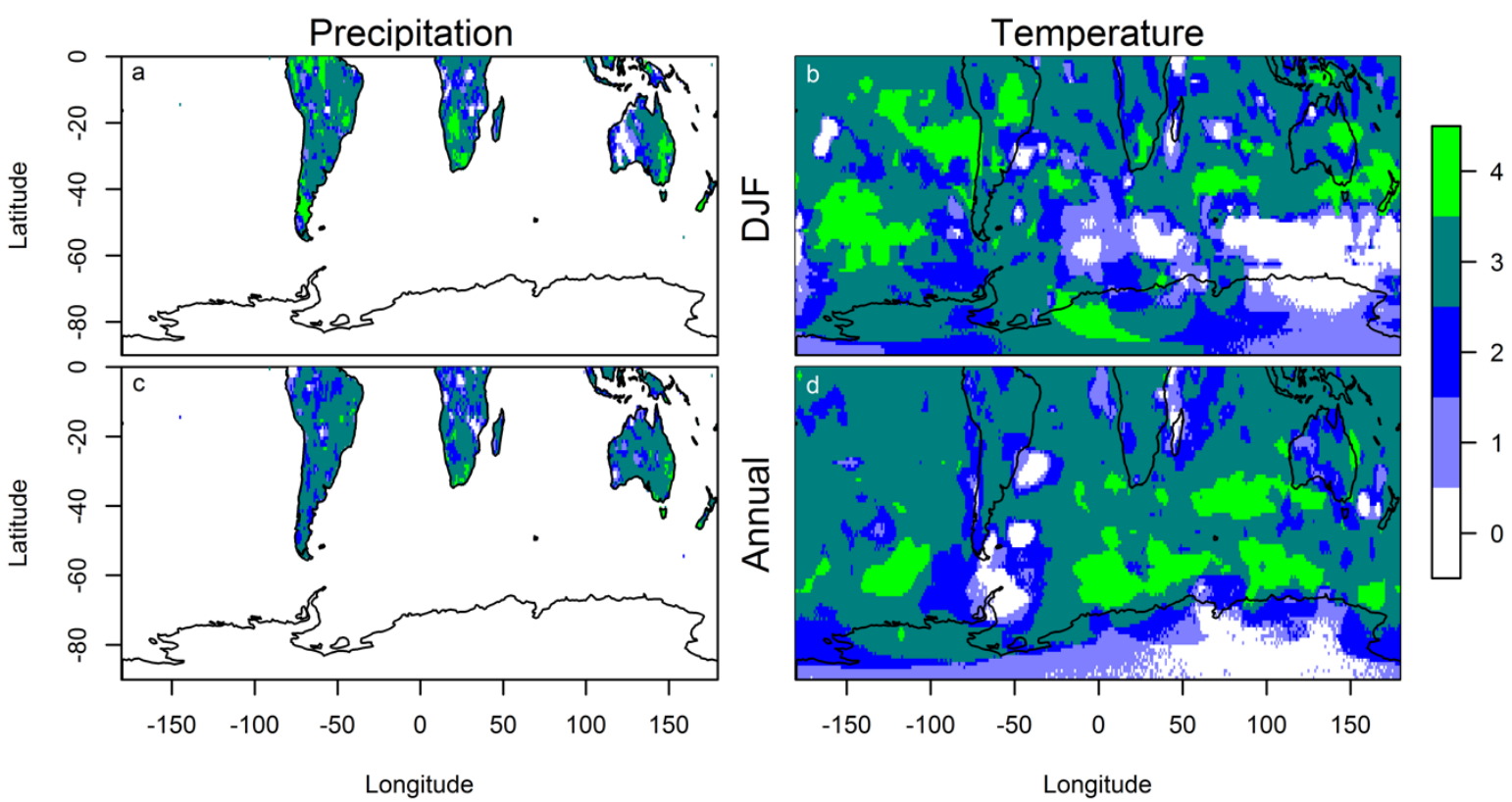

Fig. 2 The maps show for each grid point the number of stationarity criteria (Gershunov, Gallant, AIC and Sign Tests) that are fulfilled over the instrumental period (1905-2005) between SAM and precipitation $(a, c)$ or temperature $(b, d)$ for DJF $(a, b)$ and annual $(c, d)$. White colour indicates that no stability test is fulfilled, whereas light green colour means that all four stability tests are fulfilled

Over areas where the correlation between local temperature or precipitation with SAM is high and

significant, we generally also find rather stationary relationships. However, there are also exceptions

where a climate variable is significantly correlated to the SAM but the outcome of our stationarity tests 
observed in the southern Pacific Ocean between southern South America and New Zealand, and over large parts of Antarctica in the annual case. In general, a high and significant correlation does not always imply a stationary teleconnection. Note that apparently high and stationary temperature correlations over the SH oceans and Antarctica may be an artefact of the extremely low data coverage in this area especially in the early $20^{\text {th }}$ century.

\subsection{Austral summer (DJF) SAM reconstructions}

All terrestrial SH regions with a strong SAM influence are covered by our proxy network (Fig. 1; All Proxies). The locations of the proxy records obtained through the three different selection criteria (Correlation Cor, Correlation Plus Stationarity Cor \& Stat, Sign Test) are shown in Fig. 3a (Cor selection, 43 records), Fig. 3b (Cor \& Stat selection, 34 records) and Fig. 3c (Sign Test selection, 38 records). Fig. $3 d$ shows the locations of the proxy records that were used for the Villalba SAM reconstruction (3 composite tree-ring chronologies). Nine records drop out by additionally imposing the stationarity criteria (Cor \& Stat selection) to the Cor selection: these are two Antarctic ice core records, three treering records and one documentary record from South America, one tree-ring record from Tasmania, one from New Zealand and one coral record near the eastern African coast. Besides two of the three Villalba selection tree-ring chronologies, there are a total of 20 other proxy records passing through all three (Cor, Cor \& Stat and Sign Test) selection regimes. These records include nine Australasian and 

one South American documentary record.

378
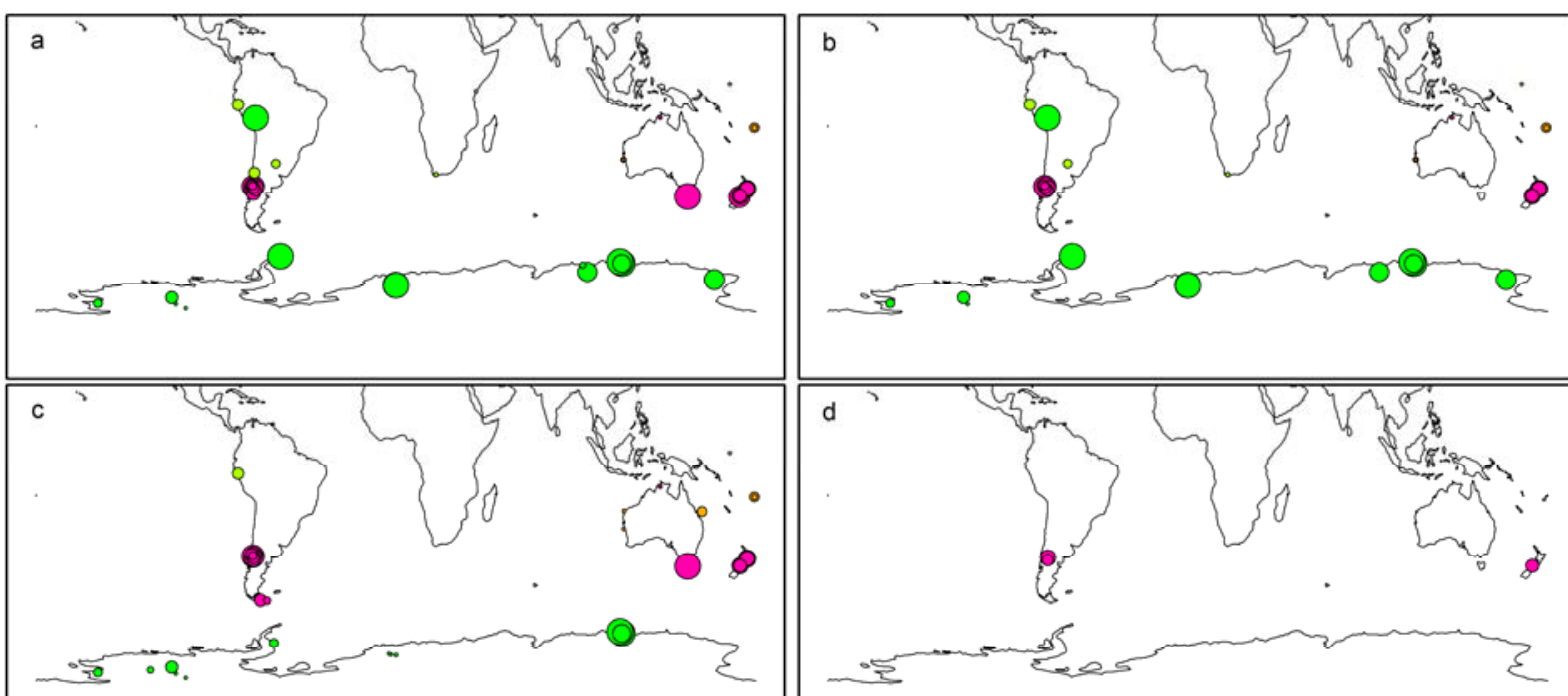

- Borehole $\quad$ Document

- Instrumental

- Lake Sediment

- Marine Sediment - Tree-ring

Speleothem

Fig. 3 Proxy networks for the Cor (a), Cor \& Stat (b), Sign Test (c) and Villalba (d) selection for DJF and the long calibration period (1905-2005). The size of the circles corresponds to the record length (between 140 and 1011 years)

A comparison of our SH summer SAM reconstructions based on the differently selected proxy record networks is shown in Fig. 4, along with the number of proxy records contributing to the reconstructions over time. All curves are 30-year loess filtered and displayed as anomalies with respect to the calibration period 1905-2005 (yellow shading). The SAM reconstruction of the All Proxies experiment is shown in the SM (Fig. S20 and S21). 


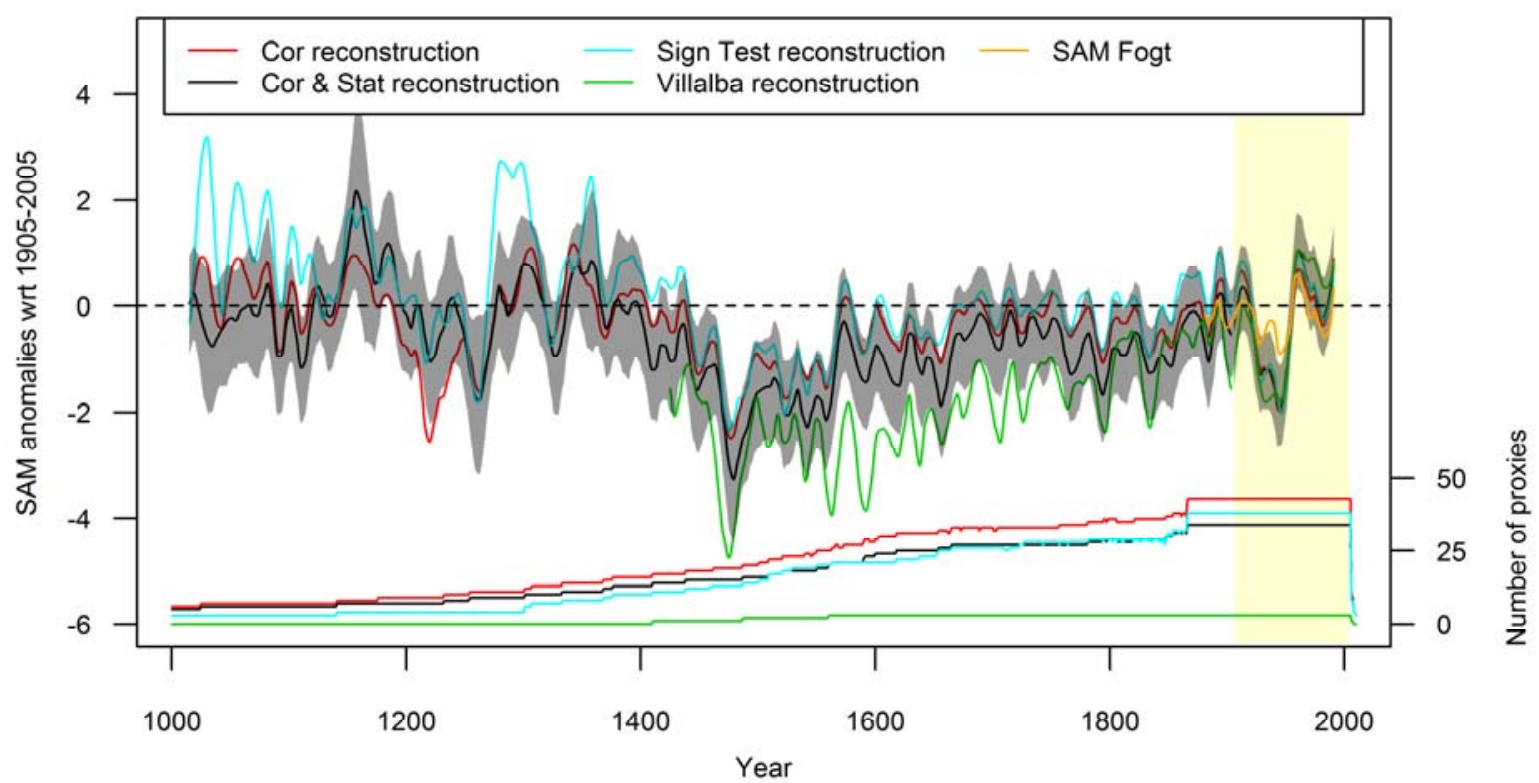

Fig. 4 30-year loess filtered ensemble median reconstructions of the DJF SAM index (anomalies with respect to 1905-2005) using different selection criteria for the proxy records (red, black and cyan) and the Villalba reconstruction (green). The Fogt SAM index is shown in orange. The grey shaded area represents the $90 \%$ confidence interval (ensemble percentiles) for the Cor \& Stat SAM reconstruction (black curve). Yellow shading marks the calibration interval 1905-2005. Additionally, the number of proxy records contributing to the respective reconstruction over time is shown at the bottom

Generally, a negative trend in the DJF SAM index can be seen until AD 1480 where the SAM index reaches exceptionally strong negative values in the perspective of its 1000 -year long history. The 30 year filtered SAM values remain negative for multiple decades (and for all proxy data selection criteria applied; Fig. 4). This negative trend is followed by a significant positive trend from ca. AD 1500 until the present.

The Villalba reconstruction extends back to AD 1400 (green curve), whereas our three new reconstructions reach back to $A D$ 1000. All the reconstructions have a similar structure of multidecadal variability (Fig. 4 and Fig. 5) but the low frequency (centennial) amplitude between the reconstructions differs considerably. Compared to the other reconstructions, the Villalba reconstruction yields the strongest negative values between AD 1400 and 1800 .

In particular, the Cor reconstruction (red curve) and the Cor \& Stat reconstruction (black curve) differ only marginally, except during AD 1150-1250. Prior to ca. AD 1400, the agreement between the individual reconstructions decreases. Note that the apparent higher variance in the reconstructed SAM indices compared to the target Fogt SAM index is due to the filtering. The proxy composites have lower inter-annual variability than the target, which is compensated with higher decadal variance in the 

case is given in SM Fig. S19 and Table S2.

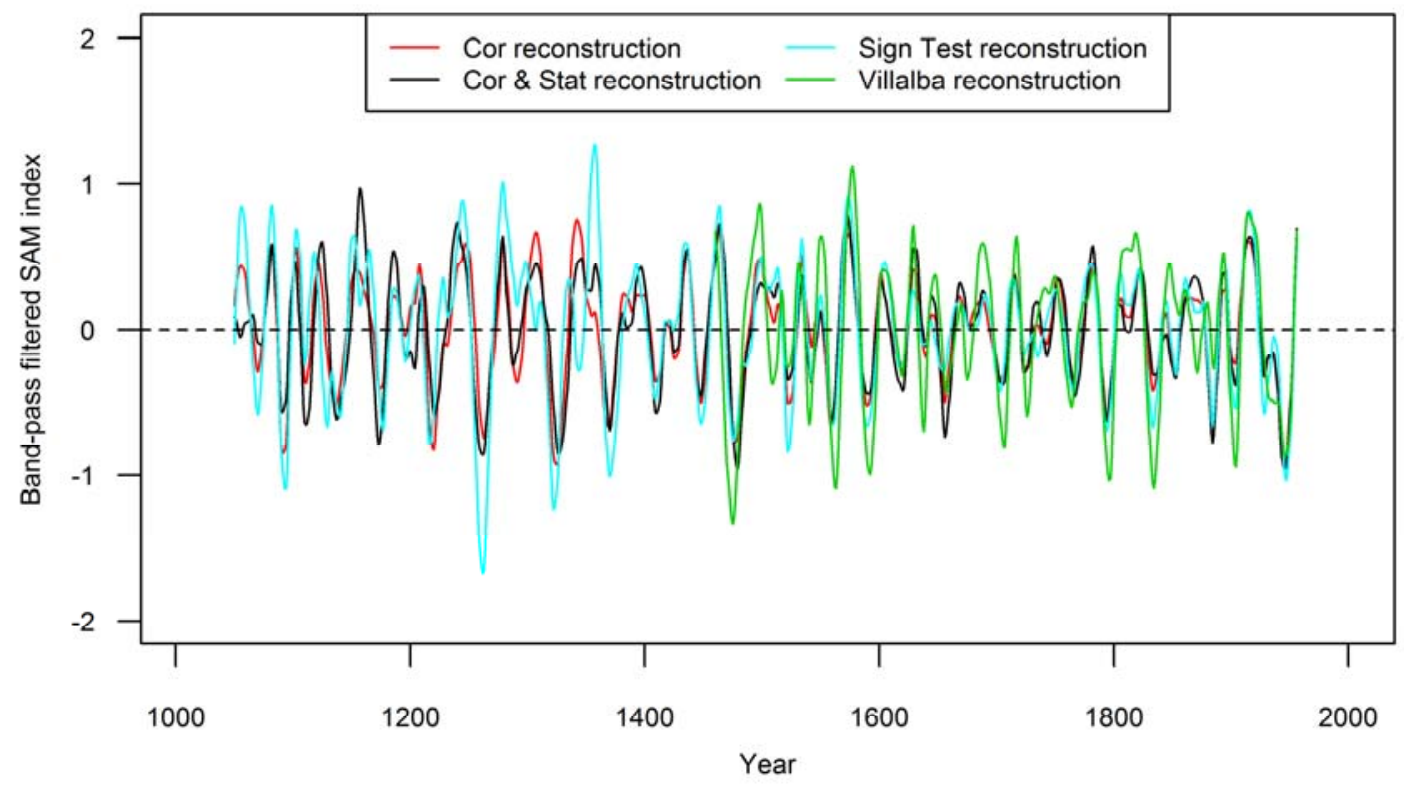

410 reconstructions are consistent with one another.

Fig. 5 30-100 year band-pass filtered DJF SAM reconstructions using the long calibration interval

In Fig. 6, the SAM reconstructions based on the shorter calibration interval 1958-1995 are compared to the reconstructions using the long calibration interval. A longer calibration interval allows for more robust stationarity testing of the proxy data, whereas the shorter more recent calibration period exhibits better data quality for the SAM index in the second half of the $20^{\text {th }}$ century. Apart from some differences in the data-sparse period prior to $A D$ 1300, the short and long calibration period reconstructions are consistent with one another. 


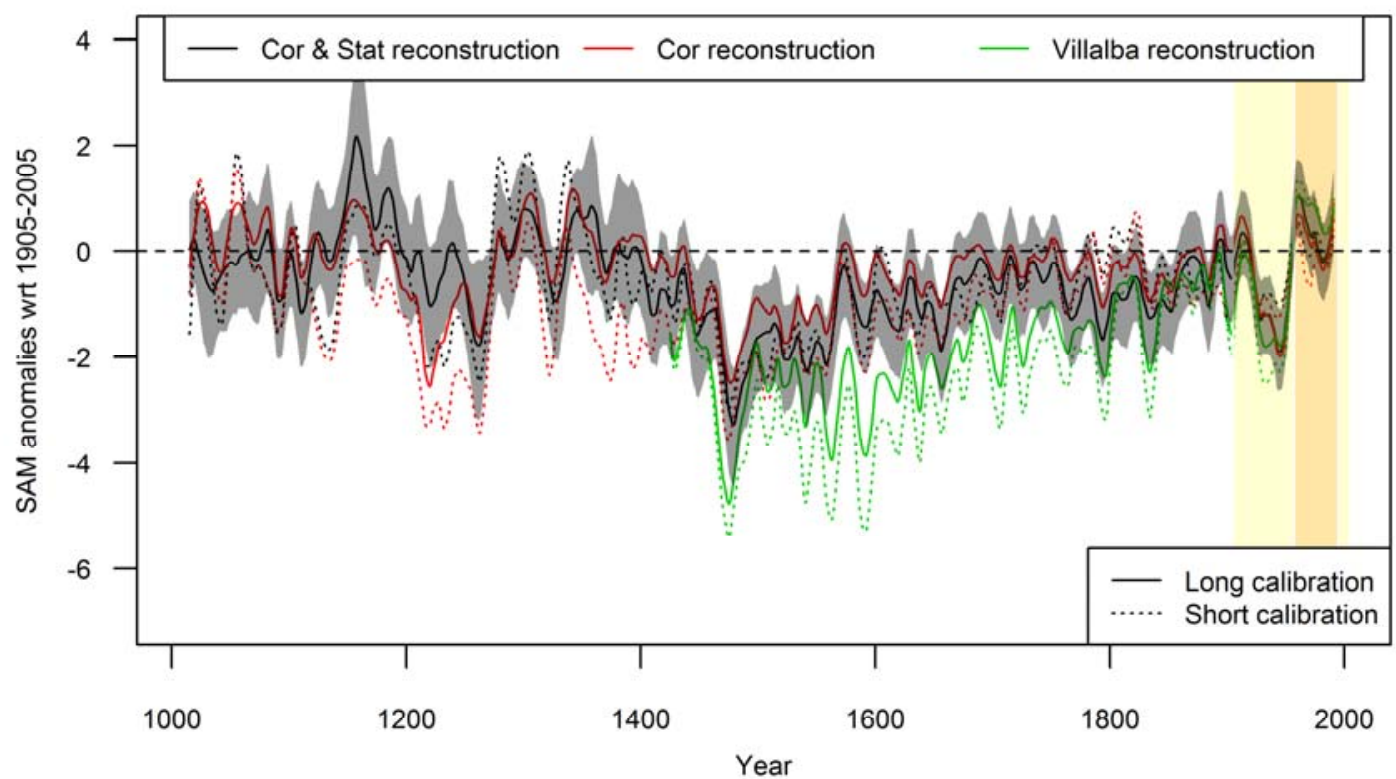

419

420

421

422

423

424

425

426

Fig. 6 Comparison of DJF SAM index reconstructions using a long (yellow shading, 1905-2005, solid lines) and short (orange shading, 1958-1995, dashed lines) calibration interval. The grey shaded area represents the $90 \%$ confidence interval (ensemble percentiles) for the black solid line

\subsection{Annual SAM reconstructions}

Similarly to Fig. 3 (for DJF), Fig. 7 shows the locations of the proxy records which were used for the different annual SAM reconstructions (25 records for Cor selection, 13 records for Cor \& Stat selection, 36 records for Sign Test selection and 27 records for the Abram selection). Both sets of proxy records that remained after Cor and Cor \& Stat selection include records from Antarctica, Australasia and South America, whereas the Abram selection does not include any records from Australasia. The 12 records not included in the Cor \& Stat selection compared to the Cor selection consist of seven tree-rings from South America and Australasia, two ice core records from the west Antarctic ice sheet, one speleothem recordfrom the Pacific Ocean, one coral record from the Indian Ocean and one borehole record near the eastern Antarctic coast line. A number of long records that are included in the Abram reconstruction did not pass our selection criteria (non-significant or non-stationary correlations with the SAM index) and were excluded for our reconstructions. There is only one ice core record (DSS Law Dome) which is present in all of the four proxy data sets. The Cor, Cor \& Stat and Sign Test selection proxy networks have one South American and three Australasian tree ring records, one South American documentary record and two Antarctic ice core records in common. Two ice core records 

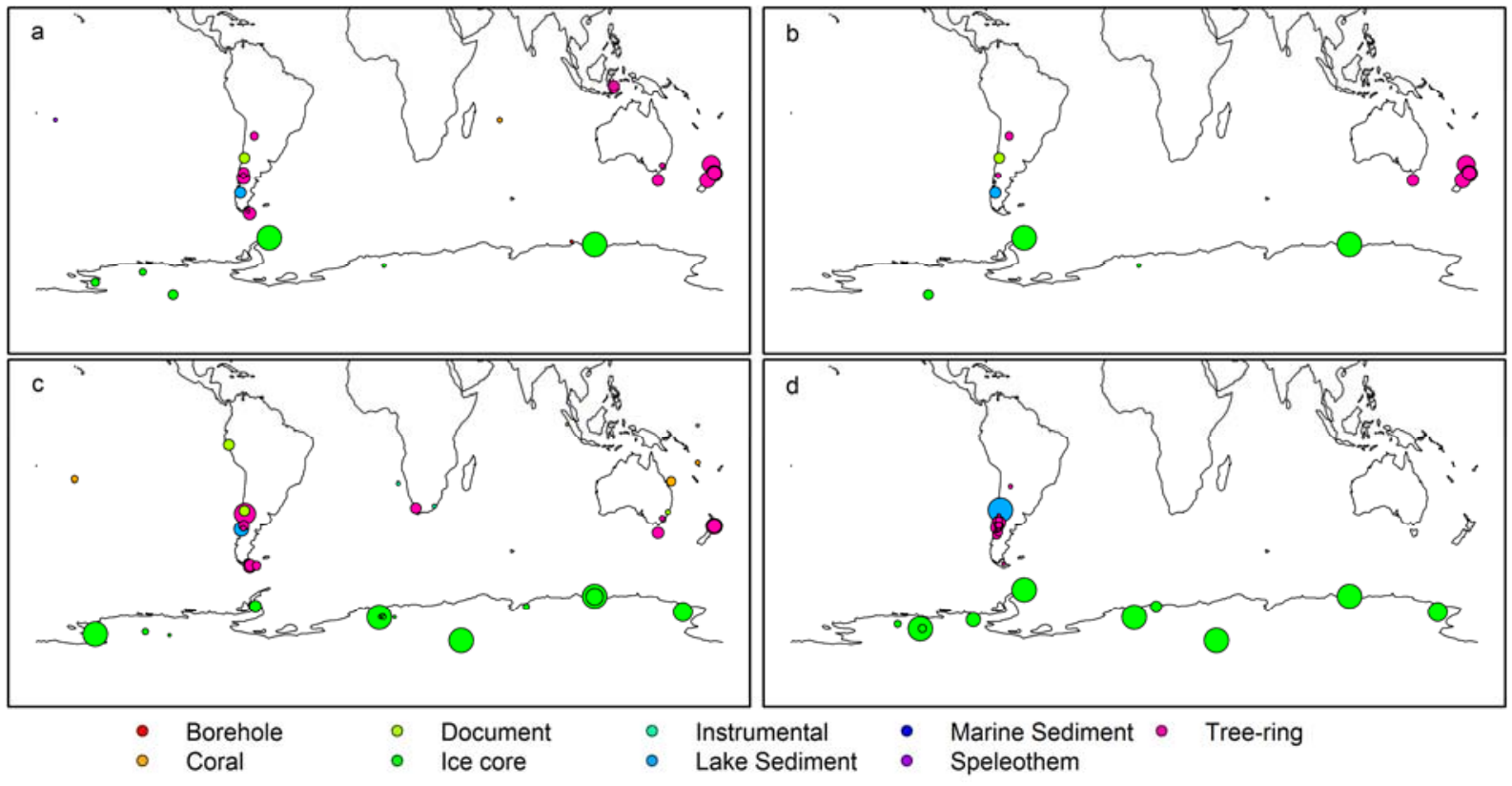

Fig. 7 Proxy networks for the Cor (a), Cor \& Stat (b), Sign Test (c) and Abram (d) selection for the annual SAM reconstruction and using the long calibration period (1905-2005). The size of the circles corresponds to the record length (between 140 and 1011 years)

Overall, the DJF SAM reconstructions look very homogenous, whereas the annual SAM reconstructions a very strong dependence on the calibration period.

Fig. 8 and Fig. 9 show the results for the annual SAM reconstructions, analogous to Fig. 4 and Fig. 6 for DJF. Only the Cor and Cor \& Stat annual SAM reconstructions using the long calibration interval yield a reconstruction that is similar to the summer SAM, i.e. a negative trend in the first half of the last millennium peaking in a minimum around $A D 1480$, followed by a positive trend until present. The agreement between the reconstructions based on the three different proxy records selection criteria is clearly reduced in the annual SAM reconstructions compared to the DJF SAM reconstructions. In particular, differences between the short and long calibration intervals are substantial for most experiments (Fig. 10). This suggests that the choice of the stationarity criteria has a stronger influence on the annual SAM reconstruction than on the DJF SAM reconstruction. Also the difference between 


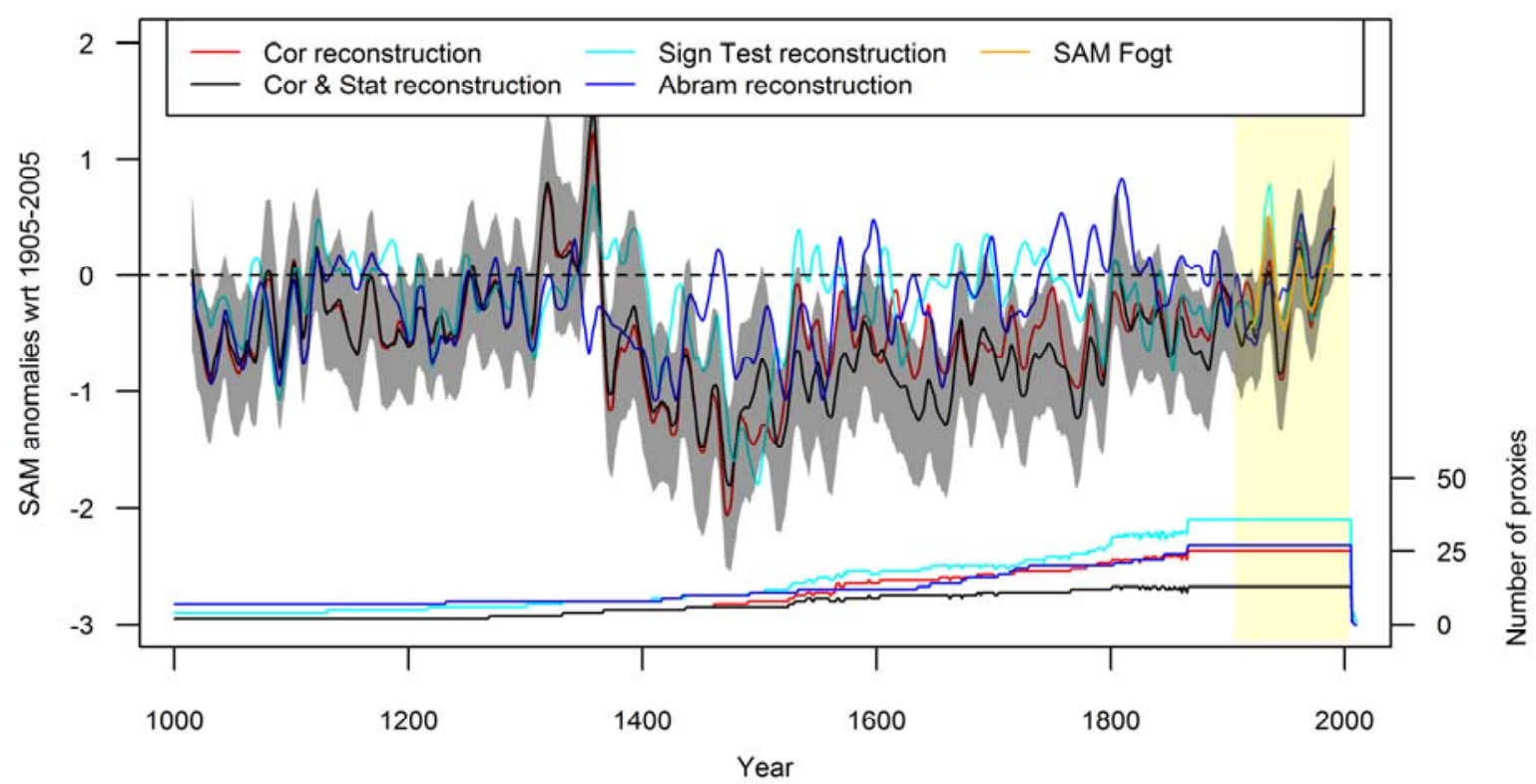

Fig. 8 30-year loess filtered ensemble median reconstructions of the annual SAM index (anomalies with respect to 1905-2005) using different selection criteria for the proxy records (red, black and cyan) and the Abram reconstruction (blue curve). The Fogt SAM index is shown in orange. The grey shaded area represents the $90 \%$ confidence interval (ensemble percentiles) for the Cor \& Stat reconstruction (black curve). Yellow shading marks the calibration interval 1905-2005. Additionally, the number of proxy records contributing to the respective reconstruction over time is shown at the bottom

The annual SAM reconstructions are very sensitive to the choice of the calibration period (long: 1905-

the results for DJF, where all SAM reconstructions are very similar, independent on the length of the 


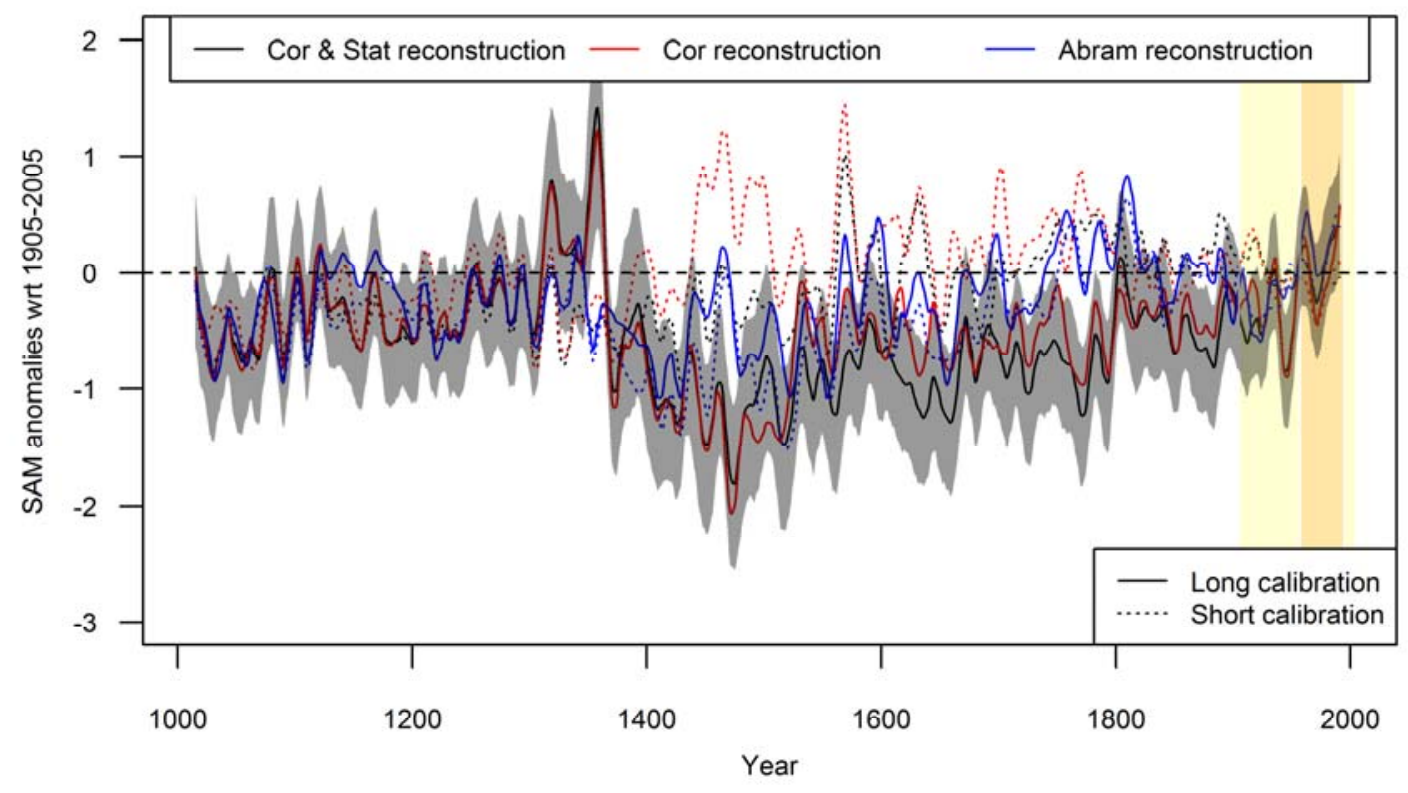

472

473

474

475

476

477

478

479

480

481

482

483

484

485

486

Fig. 9 Comparison of annual SAM index reconstructions using the long (yellow shading, 1905-2005, solid lines) and the short (orange shading, 1957-1995, dashed lines) calibration intervals. The grey shaded area represents the 90\% confidence interval (ensemble percentiles) for the Cor \& Stat reconstruction (black solid line)

\subsection{Comparison of reconstruction performance}

A comparison of the quality of the different reconstruction experiments, as measured using the

metrics described in section 2.3.3, is shown in Table 1.

Table 1 Comparative reconstruction skill and stationarity performance of the different experiments for DJF and annual SAM reconstructions. Values are shown for the long calibration (1905-2005) reconstructions (values for the short calibration 1957/58-1995 in brackets). Values in bold (italics) indicate the best (weakest) performing reconstruction regarding the respective measure/column. The values for V12 and A14 are the ones reported by the original literature. They are based on slightly different methods and not directly comparable to the other values. The "Stationarity" column indicates the number of stationarity criteria (Gershunov, Gallant, AIC and Sign Test, maximum four) which are fulfilled over the period 1905-1957. Validation statistics see SM Table S3

\begin{tabular}{|l|l|l|l|l|l|}
\hline & $\mathrm{RE}$ & $\mathrm{R}^{2}$ & $\mathrm{RMSE}$ & Std.dev. ratio & Stationarity \\
\hline DJF & & & & & \\
\hline All Proxies & $0.28(\mathbf{0 . 5 7})$ & $0.39(\mathbf{0 . 6 2})$ & $1.39(\mathbf{0 . 8 6})$ & $0.55(0.55)$ & $1(1)$ \\
\hline Cor selection & $\mathbf{0 . 3 5 ( 0 . 4 1 )}$ & $\mathbf{0 . 4 4}(0.50)$ & $\mathbf{1 . 3 1 ( 1 . 0 0 )}$ & $1.05(0.62)$ & $2(2)$ \\
\hline Cor \& Stat selection & $0.33(0.26)$ & $0.43(0.40)$ & $1.32(1.13)$ & $\mathbf{1 . 0 0 ( 0 . 6 4 )}$ & $2(3)$ \\
\hline Sign Test selection & $0.21(0.16)$ & $0.36(0.33)$ & $1.44(1.21)$ & $1.20(\mathbf{0 . 9 3})$ & $\mathbf{3}(\mathbf{4})$ \\
\hline Villalba selection & $-0.03(0.06)$ & $0.23(0.28)$ & $1.63(1.28)$ & $1.09(1.08)$ & $\mathbf{3}(3)$ \\
\hline V12 & $(\mathrm{ca} 0.4)$ & $(\mathrm{ca} 0.4)$ & $\mathrm{nd}$ & $\mathrm{nd}$ & $\mathrm{nd}$ \\
\hline & & & & & \\
\hline Annual & & & & & \\
\hline All Proxies & $\mathbf{0 . 1 6 ( 0 . 4 5 )}$ & $\mathbf{0 . 3 1 ( 0 . 5 2 )}$ & $\mathbf{0 . 7 9 ( 0 . 4 5 )}$ & $0.60(0.40)$ & $3(0)$ \\
\hline Cor selection & $0.09(0.40)$ & $0.30(0.49)$ & $\mathbf{0 . 7 9 ( 0 . 4 6 )}$ & $\mathbf{1 . 0 1 ( 0 . 7 1 )}$ & $\mathbf{4 ( 0 )}$ \\
\hline
\end{tabular}


487

488

489

490

491

492

493

494

495

496

497

498

499

500

501

502

503

504

505

506

507

508

509

\begin{tabular}{|l|l|l|l|l|l|}
\hline Cor \& Stat selection & $0.01(0.20)$ & $0.24(0.36)$ & $0.83(0.54)$ & $1.11(0.82)$ & $3(0)$ \\
\hline Sign Test selection & $0.08(0.00)$ & $0.26(0.24)$ & $0.80(0.61)$ & $1.05(0.81)$ & $\mathbf{4}(0)$ \\
\hline Abram selection & $0.10(0.31)$ & $0.24(0.41)$ & $0.82(0.50)$ & $1.03(\mathbf{0 . 9 1})$ & $\mathbf{4 ( 2 )}$ \\
\hline A14 & $0.25)$ & nd & nd & nd & nd \\
\hline
\end{tabular}

The All Proxies and Cor selection experiments yield high skill (RE, $\mathrm{R}^{2}, \mathrm{RMSE}$ ) but less stationary results.

In nearly all cases, these two reconstruction experiments score the highest and second highest values for the skill measures, but perform the worst or second worst when it comes to stationarity. Not screening the proxy records at all (All Proxies) leads to high skill scores but a very large loss of variance in the respective reconstruction (ratio of standard deviations between 0.40 and 0.60, SM Fig. S20 and S21). This indicates reduced quality of the reconstruction and a certain overfit. Furthermore, the All Proxies experiment has reduced verification skill compared to the Cor and Cor \& Stat reconstructions (SM Table S3). The Sign Test reconstructions score high stationarity results, reflecting the very restrictive underlying proxy record selection procedure, but at the cost of lower performance metrics. The reconstruction using the Villalba selection of proxy records (only three tree-ring composite chronologies) performs worst with regard to the skill measures. However, it fulfils three out of four stationarity criteria. Similarly, the reconstruction using the Abram selection of proxy records meets four (or two for the short calibration reconstruction) stationarity criteria and performs very well in this regard.

Fig. 10 shows the evolution of the RE statistics over the whole reconstruction period. The results for DJF indicate skill over the whole reconstruction period ( $R E>0$ ) for all reconstruction (except the early part of the Villalba reconstruction). This indicates that the long proxy records covering the entire millennium have a strong SAM signal and the shorter records introduce only a minor amount of additional information. In the annual case, the RE values show skill from around AD 1400 onwards. Generally, the RE statistics are better for the summer SAM reconstructions than for the annual results. Note that skill metrics like the RE are extremely sensitive to the validation period chosen. Therefore, comparisons with numbers reported in literature are of limited value (V12 and A14 in Table 1). 
511 interval as this experiment performs well in all metrics shown in Table 1 and SM Table S3.

512

\section{3}

514

\section{5}

516

517

518

519

520
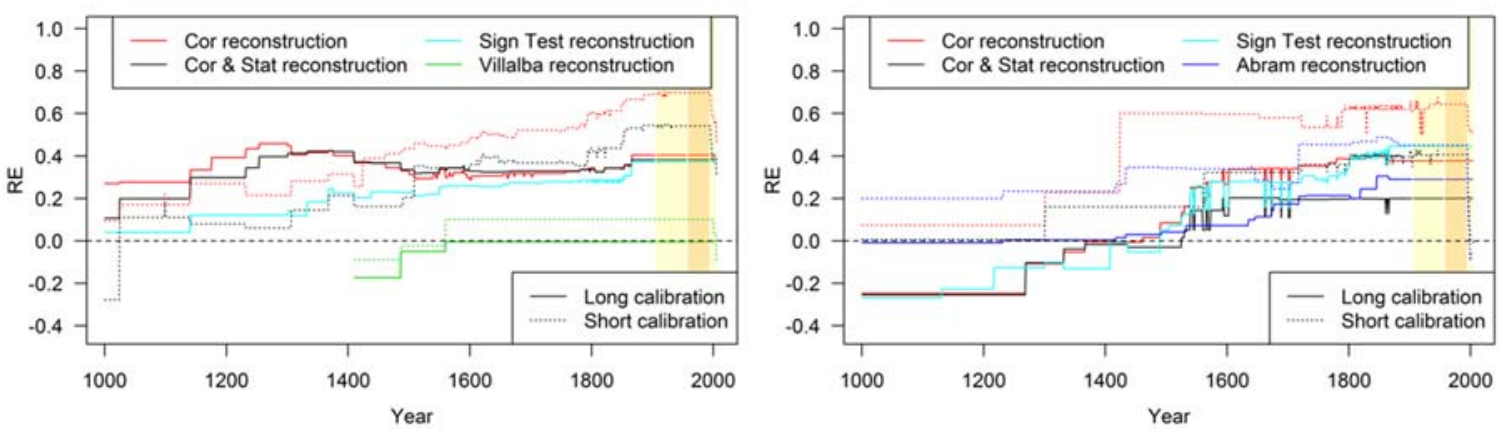

Fig. 10 Comparison of RE values between AD 1000 and 2005 for DJF (left) and annual (right) SAM reconstructions

\subsection{External forcing}

The analysis of running correlations between $\mathrm{SAM}$ and $\mathrm{CO}_{2}$ or solar forcing did not yield significant correlations (not shown). However, an epoch analysis reveals that the SAM index shows a significant negative anomaly (relative to five years before the eruption) one year after the Samalas eruption in AD 1257 (Fig. 11). This is the only significant response to all considered eruptions. The mean of all included eruptions does not show a significant response (dark blue bold line in Fig. 11).

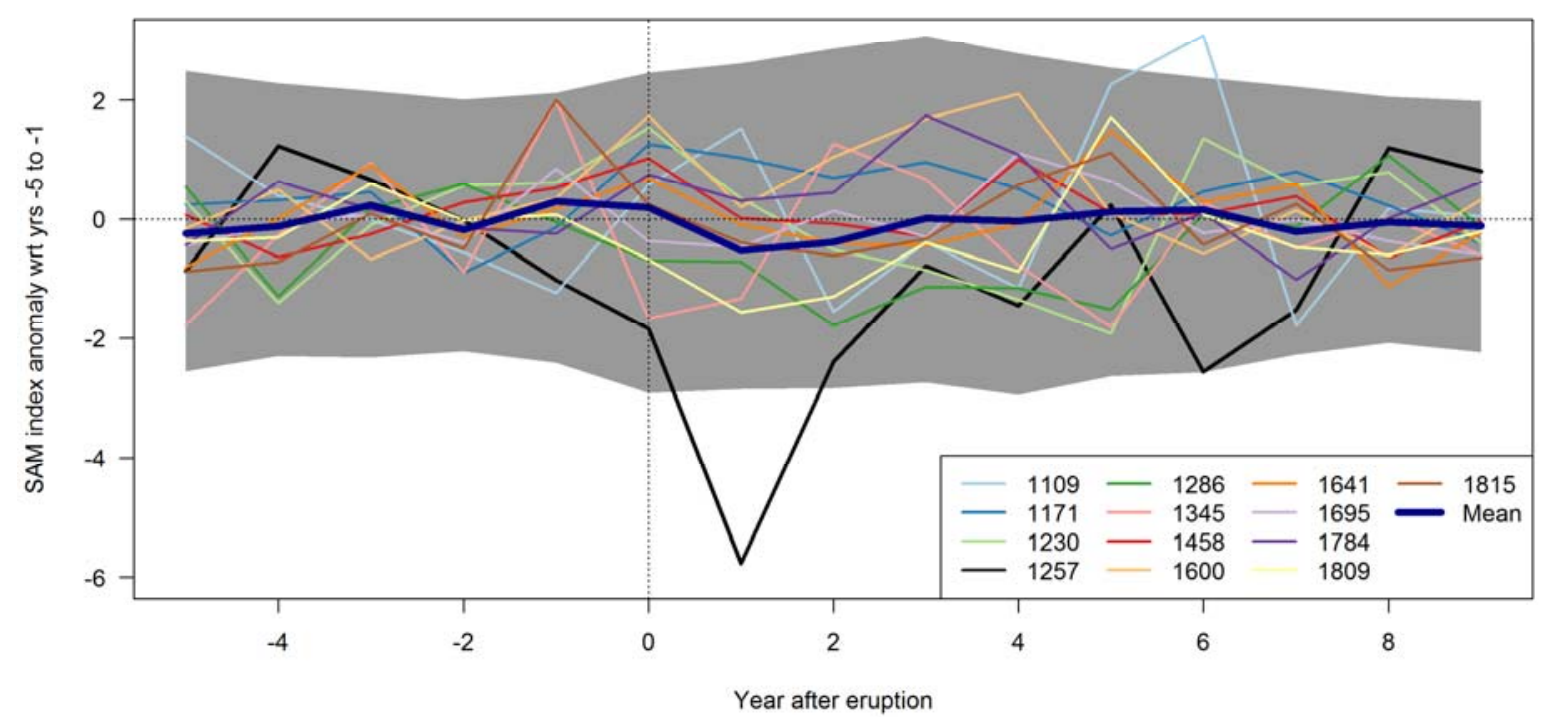

Fig. 11 Epoch analysis showing the SAM response to volcanic eruptions: SAM index relative to the years 5 to 1 prior to the volcanic eruptions. Year 0 (vertical dotted line) indicates the year of the eruption. Grey shading shows the Bonferroni-corrected familywise 5-95\% range of expected SAM response over all years within the last millennium. Bold blue is the average of all 13 eruptions. Data are from the DJF Cor \& Stat SAM reconstruction (long calibration) 


\subsection{Trend analysis}

528 The calculation of 60-year trends in the DJF Cor \& Stat SAM reconstruction allows us to assess if recent

529 trends in the SAM are outside natural variability (as calculated from instrumental and model data). We

530 find that the 5-95\% range of all pre-industrial (prior to 1850) trends in the reconstruction and in the

531 CMIP5 control simulations are very similar (Fig. 12). The positive trend in the most recent 60 -years of

532

533

534

535 our SAM reconstruction (1946-2005) lies outside the 5-95\% range of pre-industrial variability and CMPI5 control simulation trends. This is also the case for the other SAM indices, such as the Marshall (1958-2017), HadSLP2r (1952-2011, only outside trends of CMIP5 control simulations) and $20^{\text {th }}$ Century Reanalysis (1952-2011) SAM. All these results also hold true, if the reconstruction is calculated by weighting the proxy records by their detrended correlation with the target SAM over the calibration period (Fig. S22). The validation with noise-proxy reconstructions yields a significant maximal trend over the industrial period in $13 \%$ of the cases, whereas the most recent trend was significant in only $3 \%$ of the reconstructions. In addition, for $94.4 \%$ of the 1000 ensemble members (of the DJF Cor \& Stat SAM reconstruction) the largest trend over the industrial period lies outside the 5-95\% range of preindustrial trends.

Fig. 12 Left: 5-95\% range of 60-year preindustrial SAM trends in the DJF Cor \& Stat reconstruction together with the most recent (1946-2005, solid red) and maximal (1941-2000, dashed red) trend over the industrial period. Middle: 5-95\% range of 60-year trends in the CMIP5 control simulations (from Bindoff et al. 2014). Right: Marshall SAM trend (1958-2017, green), HadSLP2r (1952-2011, blue) and 20CR SAM trends (1952-2011, cyan) 


\section{Discussion}

549 We have shown that the austral summer SAM reconstructions are notably robust with respect to different proxy record selections and to changes in the length of the calibration period. In addition, they all agree well with the Villalba SAM reconstruction. Such a high robustness and good accordance to the Abram SAM reconstruction could not be observed for our annual SAM reconstructions. Furthermore, we found that recent trends in the SAM lie outside the range of pre-industrial variability and that the SAM index shows a significant response to the Samalas eruption in 1257. In the following we will discuss some consequences of these results and give possible explanations for some of the observed phenomena.

\subsection{Summer (DFJ) SAM reconstructions}

559 Our summer SAM reconstructions are remarkably robust to changes in proxy selection criteria and calibration period length. The qualitative evolution of the SAM index and multi-decadal fluctuations agree very well among the different experiments performed. There is slightly less agreement in the early period of the reconstructions prior to $c a . A D 1400$, which is likely due to the reduced number of available predictor datasets. However, the reconstructions showed some discrepancies at low frequencies. Such discrepancies are often observed in statistical reconstructions (e.g. von Storch et al. 2004; Smerdon and Pollack 2016 and references therein). Therefore, the amplitude of the negative SAM anomaly between ca. AD 1450-1600 remains debatable and may range between -1.0 and -2.8 index values (normalised units relative to 1905-2005).

Our new reconstructions show SAM histories that compare very well to the Villalba SAM reconstruction. This is remarkable since ours are based on much larger sets of proxy records, compared to only three tree-ring composite chronologies in V12. But the SAM proxy records in V12 were chosen

571 very carefully, using rigorous and state of the art methods to extract a strong SAM signal out of the highly replicated tree-ring records. Forty-seven chronologies were integrated in just three tree-ring 
composite chronologies. Joining individual chronologies to composite records reduces local noise, which is not related to climate, and enhances the common signal related to climate at regional scale. While the Villalba reconstruction shows lower skill compared to our new results, it fulfils three out of four stationarity criteria (Table 1). This corroborates earlier findings that few high-quality predictors may lead to better reconstructions than large proxy collections with many noisy records (Pauling et al. 2003; Christiansen and Ljungqvist 2017).

The Cor and Cor \& Stat reconstructions yield a very similar SAM history and performance metrics, with the latter having slightly better stationarity at the cost of reduced skill metrics. This suggests that the correlation based selection method, which is commonly used in climate reconstructions (Mann et al. 2008; Jones et al. 2009a), also selects relatively stationary predictors. That is, the independence of the summer SAM reconstructions on the length of the calibration period and stationarity criteria used can be seen as an argument that there is a stationary relationship between the proxy records and the SAM. Additionally, it suggests that, at least for the long calibration windows, the best correlating proxy records are also the most stationary ones.

The ratio of standard deviations between reconstruction and target SAM data emphasises the necessity of careful selection of proxy records, since the inclusion of all proxy records without any selection leads to strongly reduced variability and, in addition, to weak performance in terms of stationarity. This suggests an overfit in the All Proxies reconstruction, and the high skill values of this experiment emphasise the limitations of these metrics (e.g. Neukom et al. 2014; Werner and Tingley 2015). Note that to be consistent with literature (A14; V12), only calibration skill metrics are shown in Table 1. Out of sample (validation) values are lower for the All Proxies experiment (average $\mathrm{RE}=0.00$ ) than for the Cor selection (0.20) or Cor \& Stat selection (0.20) (SM Table S3). This also points towards an overfit in the All Proxies experiment ("good" calibration but reduced validation skill).

We consider the proxy records remaining in all of the three long calibration selections (Cor, Cor \& Stat and Sign Test) as stationary and high-quality records. These 22 records (including two out of three Villalba selection tree-ring chronologies) for DJF and seven records for the annual season are 
particularly well suited for reconstruction purposes because they have significant correlations with the SAM and pass all our stationarity criteria.

\subsection{Annual SAM reconstructions}

Compared to the DJF reconstructions, the annual SAM index reconstructions show a stronger dependence on the choice of the calibration period and on the selection criteria for the proxy records. Our annual SAM reconstructions differ considerably from the annual Abram SAM reconstruction, whereas this was not the case for our DJF SAM reconstructions when compared to the DJF Villalba SAM reconstruction. We see various factors as possible explanations for the discrepancies in the annual SAM reconstructions. In contrast to the Abram SAM reconstruction, our reconstructions include proxy records from the Australasian domain. Hence, our reconstructions may capture the more complete hemispheric character of the SAM, whereas the Abram reconstruction is more likely to represent a component of the SAM specific to the South American - Antarctic Peninsula sector. Furthermore, a considerable proportion of the proxy records in our dataset are mainly summer sensitive (e.g. midlatitude tree-rings), which may lead to a summer bias and thus weaker performance in annual reconstructions. Beyond this, proxy records in the core centre of action of the SAM are very sparse, and the ice core records introduce a spatial bias for high latitudes as they are all clustered in Antarctica. We consider these temporal and spatial distribution biases of the proxy records and our restrictive selection due to the stationarity criteria as possible explanations for the majority of the differences between the reconstructions. Temporal discrepancies between our new reconstruction and the V12 and A14 reconstructions may point to changing teleconnection patterns during March to November, since differences between the reconstructions for the summer SAM index were marginal. This is in line with earlier findings of the seasonal breakdown of the SAM's zonal symmetry outside the summer season (Jones et al. 2009b; Ding et al. 2012).

At locations where we have proxy records, the stationarity between local climate and SAM tends to be better for DJF compared to the annual period. Moreover, the inhomogeneous distribution of non- 
stationary regions across the SH suggests that the influence of the SAM index is modulated to some extent by regional effects in each continent. As a consequence, proxy records from a single sub-domain may not be representative for the commonly used hemispheric SAM index.

\subsection{Trend analysis}

The result of our trend analysis shows that $94.4 \%$ of the ensemble members of the DJF Cor \& Stat SAM reconstruction contain a trend during the industrial period which exceeds the $5-95 \%$ range of natural variability, which is "very likely" according to the terminology used in the Fifth Assessment Report (AR5) of the Intergovernmental Panel on Climate Change (IPCC). The outcome, that the largest trend over the industrial period and the most recent SAM trend in our reconstruction both lie outside the 595\% range of pre-industrial trends, is in line with earlier findings that recent positive SAM trends are outside the range of natural variability (Gillett et al. 2013; Bindoff et al. 2014). Stratospheric ozone depletion leads to increased and poleward shifted westerlies circling Antarctica, especially during austral summer, as reported by(Karpechko et al. 2008; McLandress et al. 2010; Polvani et al. 2010; Son et al. 2010; Sigmond et al. 2011). Similarly, increased GHG concentrations stand in connection with stronger positive SAM index values (Karpechko et al. 2008; Son et al. 2010; Sigmond et al. 2011; Swart and Fyfe 2012; Gillett and Fyfe 2013). Hence, there is some confidence that these two phenomena have contributed significantly to the exceptionally large recent positive SAM trends.

\subsection{Solar, GHG and volcanic forcing}

Our SAM reconstructions do not show a significant correlation with both solar and $\mathrm{GHG}\left(\mathrm{CO}_{2}\right)$ forcing over the last millennium. The mean of the SAM index response over all considered volcanic eruptions does not show a significant response either (Fig. 11). However, epoch analysis reveals a significant response of the SAM index to the Samalas eruption in AD 1257. The year AD 1258 has the most negative SAM value in our reconstruction (Cor, Cor \& Stat, Sign Test). This matches the year with the highest aerosol optical depth over the last 2000 years (Sigl et al. 2015b). This is, to our knowledge, the 
first evidence for a climatic response to the Samalas eruptions in the $\mathrm{SH}$, and in line with recent findings from the Northern Hemisphere (Guillet et al. 2017). The non-significant response of the mean could be explained through strong modulation of the forcing by internal variability (McGraw et al. 2016). This is possibly the reason why only the largest event shows a significant response in the SAM reconstruction (Fig. 11). However, the season and location of an eruption also plays an important role for the distribution of the aerosols and resulting climatic effects (Hegerl et al. 2006; Kravitz and Robock 2011; Toohey et al. 2011) and hence for the influence on the SAM.

\section{Conclusions}

In this paper we present new reconstructions of the annual SAM index and extend the austral summer SAM index back to the year AD 1000. Generally, a negative trend in the SAM index prevails during the first half of the millennium until around $A D$ 1480. This negative trend is followed by a significant positive trend until the present. We apply a range of selection criteria to choose the best and most stationary proxy records for SAM reconstructions. Fewer but high quality proxy records generally yield very good results in terms of stationarity and retention of variance in the reconstructions. The DJF SAM reconstructions are robust with respect to different stationarity criteria, and different proxy record selections yield consistent results. This is different for the annual SAM reconstructions, where similar robustness to proxy record selection and stationarity could not be confirmed. This may point to nonstationary teleconnection patterns, a lack of high quality proxy data for the non-summer seasons or difficulties with calibration related to sparse observational data in high southern latitudes.

For comprehensive large-scale and spatially explicit climate reconstructions, we recommend applying stationarity criteria in the proxy record selection procedures. This is particularly important for reconstructions of circulation indices, where teleconnections play an important role and the core centres of action often lack proxy coverage.

We find no significant response of the SAM to solar, volcanic and $\mathrm{CO}_{2}$ forcing, except for the AD 1257 
eruption of Samalas, which was followed by the most negative SAM value found over the last millennium.

Pre-industrial variability in the summer SAM trends agree very well with model simulated trends. The most recent trends in the summer SAM lie outside the 5-95\% range of pre-industrial variability.

Given the influence of the SAM on the entire SH climate, our results shed light on the importance of teleconnection stationarity and may serve as a foundation for further analyses on SH dynamics and understanding of its climate in the past, present and future.

Data availabilityOur proxy data and reconstruction results are available at the NOAA paleoclimatology database [link]. The input proxy databases are available at https://www.ncdc.noaa.gov/paleosearch/study/16196 (data labelled N14 in SM Table S4 and S5), https://doi.org/10.6084/m9.figshare.c.3285353 $\quad$ (P17), https://www.ncdc.noaa.gov/paleosearch/study/13673 (V12), and https://www.ncdc.noaa.gov/paleo/study/22589 (S17).

\section{Conflict of interest}

The authors declare that they have no conflict of interest.

\section{References}

Abram NJ, Mulvaney R, Vimeux F, Phipps SJ, Turner J, England MH (2014) Evolution of the Southern Annular Mode during the past millennium. Nature Climate change 4:564-569. doi: 10.1038/nclimate2235

Allan R, Ansell T (2006) A New Globally Complete Monthly Historical Gridded Mean Sea Level Pressure Dataset (HadSLP2): 1850-2004. J. Climate 19:5816-5842. doi: 10.1175/JCLI3937.1 Arblaster JM, Meehl GA (2006) Contributions of External Forcings to Southern Annular Mode Trends. J. Climate 19:2896-2905. doi: 10.1175/JCLI3774.1

Bindoff NL, Stott PA, AchutaRao KM, Allen MR, Gillett N, Gutzler D, Hansingo K, Hegerl G, Hu Y, Jain S, Mokhov II, Overland J, Perlwitz J, Sebbari R, Zhang X (2014) Detection and Attribution of Climate Change: From Global to Regional. In: Stocker TF, Qin D, Plattner G-K, Tignor M, Allen SK, Boschung J, Nauels A, Xia Y, Bex V, Midgley PM (eds) Climate Change 2013 - The Physical Science Basis. Cambridge University Press, Cambridge, pp 867-952

Bradley RS, Diaz HF, Kiladis GN, Eischeid JK (1987) ENSO signal in continental temperature and precipitation records. Nature 327:497-501. doi: 10.1038/327497a0

Bromwich DH, Parish TR (1998) Meteorology of the Antarctic. In: Karoly DJ, Vincent DG (eds) Meteorology of the Southern Hemisphere. American Meteorological Society, Boston, MA, s.I., pp 175-200 
Brönnimann S, Jacques-Coper M, Rozanov E, Fischer AM, Morgenstern O, Zeng G, Akiyoshi H, Yamashita Y (2017) Tropical circulation and precipitation response to ozone depletion and recovery. Environ. Res. Lett. 12:64011. doi: 10.1088/1748-9326/aa7416

Bürger G, Cubasch U (2005) Are multiproxy climate reconstructions robust? Geophys. Res. Lett. 32:n/a-n/a. doi: 10.1029/2005GL024155

Cai W, Cowan T (2006) SAM and regional rainfall in IPCC AR4 models: Can anthropogenic forcing account for southwest Western Australian winter rainfall reduction? Geophys. Res. Lett. 33. doi: 10.1029/2006GL028037

Christiansen B, Ljungqvist FC (2017) Challenges and perspectives for large-scale temperature reconstructions of the past two millennia. Rev. Geophys. 55:40-96. doi: 10.1002/2016RG000521

Compo GP, Whitaker JS, Sardeshmukh PD, Matsui N, Allan RJ, Yin X, Gleason BE, Vose RS, Rutledge G, Bessemoulin P, Brönnimann S, Brunet M, Crouthamel RI, Grant AN, Groisman PY, Jones PD, Kruk MC, Kruger AC, Marshall GJ, Maugeri M, Mok HY, Nordli $\varnothing$, Ross TF, Trigo RM, Wang XL, Woodruff SD, Worley SJ (2011) The Twentieth Century Reanalysis Project. Q.J.R. Meteorol. Soc. 137:1-28. doi: 10.1002/qj.776

Cook ER, Briffa KR, Jones PD (1994) Spatial regression methods in dendroclimatology: A review and comparison of two techniques. Int. J. Climatol. 14:379-402. doi: 10.1002/joc.3370140404

Ding Q, Steig EJ, Battisti DS, Wallace JM (2012) Influence of the Tropics on the Southern Annular Mode. J. Climate 25:6330-6348. doi: 10.1175/JCLI-D-11-00523.1

Fogt RL, Perlwitz J, Monaghan AJ, Bromwich DH, Jones JM, Marshall GJ (2009) Historical SAM Variability. Part II: Twentieth-Century Variability and Trends from Reconstructions, Observations, and the IPCC AR4 Models. J. Climate 22:5346-5365. doi: 10.1175/2009JCLI2786.1

Fogt RL, Bromwich DH, Hines KM (2011) Understanding the SAM influence on the South Pacific ENSO teleconnection. Clim Dyn 36:1555-1576. doi: 10.1007/s00382-010-0905-0

Gallant AJE, Phipps SJ, Karoly DJ, Mullan AB, Lorrey AM (2013) Nonstationary Australasian Teleconnections and Implications for Paleoclimate Reconstructions. J. Climate 26:8827-8849. doi: 10.1175/JCLI-D-12-00338.1

Gergis J, Gallant AJE, Braganza K, Karoly DJ, Allen K, Cullen L, D'Arrigo R, Goodwin I, Grierson P, McGregor S (2012) On the long-term context of the 1997-2009 'Big Dry' in South-Eastern Australia: Insights from a 206-year multi-proxy rainfall reconstruction. Climatic change 1:1. doi: 10.1007/s10584-011-0263-x

Gergis J, Neukom R, Gallant AJE, Karoly DJ (2016) Australasian Temperature Reconstructions Spanning the Last Millennium. J. Climate 29:5365-5392. doi: 10.1175/JCLI-D-13-00781.1

Gershunov A, Schneider N, Barnett T (2001) Low-Frequency Modulation of the ENSO-Indian Monsoon Rainfall Relationship: Signal or Noise?: Journal of Climate. J. Climate 14:2486-2492. doi: 10.1175/1520-0442(2001)014<2486:LFMOTE>2.0.CO;2

Gillett NP, Fyfe JC (2013) Annular mode changes in the CMIP5 simulations. Geophys. Res. Lett. 40:1189-1193. doi: 10.1002/grl.50249

Gillett NP, Kell TD, Jones PD (2006) Regional climate impacts of the Southern Annular Mode. Geophys. Res. Lett. 33. doi: 10.1029/2006GL027721

Gillett NP, Fyfe JC, Parker DE (2013) Attribution of observed sea level pressure trends to greenhouse gas, aerosol, and ozone changes. Geophys. Res. Lett. 40:2302-2306. doi: 10.1002/grl.50500

Gong D, Wang S (1999) Definition of Antarctic Oscillation index. Geophys. Res. Lett. 26:459-462. doi: 10.1029/1999GL900003

Guillet S, Corona C, Stoffel M, Khodri M, Lavigne F, Ortega P, Eckert N, Sielenou PD, Daux V, Churakova OV, Davi N, Edouard J-L, Zhang Y, Luckman BH, Myglan VS, Guiot J, Beniston M, Masson-Delmotte V, Oppenheimer C (2017) Climate response to the Samalas volcanic eruption in 1257 revealed by proxy records. Nature Geosci 10:123-128. doi: 10.1038/ngeo2875 
Gupta AS, England MH (2006) Coupled Ocean-Atmosphere-Ice Response to Variations in the Southern Annular Mode. J. Climate 19:4457-4486. doi: 10.1175/JCLI3843.1

Harris I, Jones PD, Osborn TJ, Lister DH (2014) Updated high-resolution grids of monthly climatic observations - the CRU TS3.10 Dataset. Int. J. Climatol. 34:623-642. doi: 10.1002/joc.3711

Haurwitz MW, Brier GW (1981) A Critique of the Superposed Epoch Analysis Method: Its Application to Solar-Weather Relations. Mon. Wea. Rev. 109:2074-2079. doi: 10.1175/15200493(1981)109<2074:ACOTSE>2.0.CO;2

Hegerl GC, Crowley TJ, Hyde WT, Frame DJ (2006) Climate sensitivity constrained by temperature reconstructions over the past seven centuries. Nature 440:1029-1032. doi: 10.1038 /nature04679

Hendon HH, Thompson DWJ, Wheeler MC (2007) Australian Rainfall and Surface Temperature Variations Associated with the Southern Hemisphere Annular Mode. J. Climate 20:2452-2467. doi: 10.1175/JCLI4134.1

Ho M, Kiem AS, Verdon-Kidd DC (2012) The Southern Annular Mode: A comparison of indices. Hydrol. Earth Syst. Sci. 16:967-982. doi: 10.5194/hess-16-967-2012

Holm S (1979) A Simple Sequentially Rejective Multiple Test Procedure. Scandinavian Journal of Statistics 6:65-70

Jones PD, Briffa KR, Osborn TJ, Lough JM, van Ommen TD, Vinther BM, Luterbacher J, Wahl ER, Zwiers FW, Mann ME, Schmidt GA, Ammann CM, Buckley BM, Cobb KM, Esper J, Goosse H, Graham N, Jansen E, Kiefer T, Kull C, Kuttel M, Mosley-Thompson E, Overpeck JT, Riedwyl N, Schulz M, Tudhope AW, Villalba R, Wanner H, Wolff E, Xoplaki E (2009a) High-resolution palaeoclimatology of the last millennium: A review of current status and future prospects. The Holocene 19:3-49. doi: 10.1177/0959683608098952

Jones JM, Fogt RL, Widmann M, Marshall GJ, Jones PD, Visbeck M (2009b) Historical SAM Variability. Part I: Century-Length Seasonal Reconstructions*. J. Climate 22:5319-5345. doi: 10.1175/2009JCLI2785.1

Karoly DJ, HOPE P, Jones PD (1996) DECADAL VARIATIONS OF THE SOUTHERN HEMISPHERE CIRCULATION. Int. J. Climatol. 16:723-738. doi: 10.1002/(SICI)1097-0088(199607)16:7<723:AIDJOC54>3.0.CO;2-6

Karpechko AY, Gillett NP, Marshall GJ, Scaife AA (2008) Stratospheric influence on circulation changes in the Southern Hemisphere troposphere in coupled climate models. Geophys. Res. Lett. 35:n/an/a. doi: 10.1029/2008GL035354

Kidson JW (1988) Interannual Variations in the Southern Hemisphere Circulation. J. Climate 1:11771198. doi: 10.1175/1520-0442(1988)001<1177:IVITSH>2.0.CO;2

Kravitz B, Robock A (2011) Climate effects of high-latitude volcanic eruptions: Role of the time of year. J. Geophys. Res. 116:1657. doi: 10.1029/2010JD014448

Lefebvre W (2004) Influence of the Southern Annular Mode on the sea ice-ocean system. J. Geophys. Res. 109. doi: 10.1029/2004JC002403

Liu J, Curry JA, Martinson DG (2004) Interpretation of recent Antarctic sea ice variability. Geophys. Res. Lett. 31. doi: 10.1029/2003GL018732

Lorenz DJ, Hartmann DL (2001) Eddy-Zonal Flow Feedback in the Southern Hemisphere. J. Atmos. Sci. 58:3312-3327. doi: 10.1175/1520-0469(2001)058<3312:EZFFIT>2.0.CO;2

Manatsa D, Matarira C, Mushore TD, Mudavanhu C (2015) Southern Africa winter temperature shifts and their link to the Southern Annular Mode. Clim Dyn 45:2337-2350. doi: 10.1007/s00382-0152474-8

Mann ME, Zhang Z, Hughes MK, Bradley RS, Miller SK, Rutherford S, Ni F (2008) Proxy-based reconstructions of hemispheric and global surface temperature variations over the past two millennia. Proc Natl Acad Sci U S A 105:13252-13257. doi: 10.1073/pnas.0805721105 
Marshall GJ (2003) Trends in the Southern Annular Mode from Observations and Reanalyses. J.

Climate 16:4134-4143. doi: 10.1175/1520-0442(2003)016<4134:TITSAM>2.0.CO;2

McGraw MC, Barnes EA, Deser C (2016) Reconciling the observed and modeled Southern Hemisphere circulation response to volcanic eruptions. Geophys. Res. Lett. 43:7259-7266. doi: 10.1002/2016GL069835

McLandress C, Jonsson Al, Plummer DA, Reader MC, Scinocca JF, Shepherd TG (2010) Separating the Dynamical Effects of Climate Change and Ozone Depletion. Part I: Southern Hemisphere Stratosphere. J. Climate 23:5002-5020. doi: 10.1175/2010JCLI3586.1

Meinshausen M, Vogel E, Nauels A, Lorbacher K, Meinshausen N, Etheridge DM, Fraser PJ, Montzka SA, Rayner PJ, Trudinger CM, Krummel PB, Beyerle U, Canadell JG, Daniel JS, Enting IG, Law RM, Lunder CR, O'Doherty S, Prinn RG, Reimann S, Rubino M, Velders GJM, Vollmer MK, Wang RHJ, Weiss R (2017) Historical greenhouse gas concentrations for climate modelling (CMIP6). Geosci. Model Dev. 10:2057-2116. doi: 10.5194/gmd-10-2057-2017

Morice CP, Kennedy JJ, Rayner NA, Jones PD (2012) Quantifying uncertainties in global and regional temperature change using an ensemble of observational estimates: The HadCRUT4 data set. J. Geophys. Res. 117:n/a-n/a. doi: 10.1029/2011JD017187

Nash DJ, Pribyl K, Klein J, Neukom R, Endfield GH, Adamson GCD, Kniveton DR (2016) Seasonal rainfall variability in southeast Africa during the nineteenth century reconstructed from documentary sources. Climatic change 134:605-619. doi: 10.1007/s10584-015-1550-8

Neukom R, Luterbacher J, Villalba R, Küttel M, Frank D, Jones PD, Grosjean M, Esper J, Lopez L, Wanner $\mathrm{H}$ (2010) Multi-centennial summer and winter precipitation variability in southern South America. Geophys. Res. Lett. 37:n/a-n/a. doi: 10.1029/2010GL043680

Neukom R, Luterbacher J, Villalba R, Küttel M, Frank D, Jones PD, Grosjean M, Wanner H, Aravena JC, Black DE, Christie DA, D'Arrigo R, Lara A, Morales M, Soliz-Gamboa C, Srur A, Urrutia R, Gunten $L$ von (2011) Multiproxy summer and winter surface air temperature field reconstructions for southern South America covering the past centuries. Clim Dyn 37:35-51. doi: 10.1007/s00382010-0793-3

Neukom R, Gergis J, Karoly DJ, Wanner H, Curran M, Elbert J, González-Rouco F, Linsley BK, Moy AD, Mundo I, Raible CC, Steig EJ, van Ommen T, Vance T, Villalba R, Zinke J, Frank D (2014) Interhemispheric temperature variability over the past millennium. Nature Climate change 4:362367. doi: $10.1038 /$ nclimate 2174

PAGES 2k Consortium (2013) Continental-scale temperature variability during the past two millennia. Nature Geosci 6:339-346. doi: 10.1038/ngeo1797

PAGES 2k Consortium (2017) A global multiproxy database for temperature reconstructions of the Common Era. Sci Data 4:170088. doi: 10.1038/sdata.2017.88

Palmer JG, Cook ER, Turney CSM, Allen K, Fenwick P, Cook BI, O'Donnell A, Lough JM, Grierson P, Baker $P$ (2015) Drought variability in the eastern Australia and New Zealand summer drought atlas (ANZDA, CE 1500-2012) modulated by the Interdecadal Pacific Oscillation. Environ. Res. Lett. 10:124002. doi: 10.1088/1748-9326/10/12/124002

Pauling A, Luterbacher J, Wanner H (2003) Evaluation of proxies for European and North Atlantic temperature field reconstructions. Geophys. Res. Lett. 30:603. doi: 10.1029/2003GL017589

Petris G, Petrone S (2011) State Space Models in R. J. Stat. Soft. 41. doi: 10.18637/jss.v041.i04 Pittock AB (1984) On the reality, stability and usefulness of Southern Hemisphere teleconnections. Australian Meteorological Magazine 32

Polvani LM, Waugh DW, Correa GJP, Son S-W (2010) Stratospheric Ozone Depletion: The Main Driver of Twentieth-Century Atmospheric Circulation Changes in the Southern Hemisphere. J. Climate 24:795-812. doi: 10.1175/2010JCLI3772.1 
Reason CJC, Rouault M (2005) Links between the Antarctic Oscillation and winter rainfall over western South Africa. Geophys. Res. Lett. 32. doi: 10.1029/2005GL022419

Santer BD, Wigley TML, Boyle JS, Gaffen DJ, Hnilo JJ, Nychka D, Parker DE, Taylor KE (2000) Statistical significance of trends and trend differences in layer-average atmospheric temperature time series. J. Geophys. Res. 105:7337-7356. doi: 10.1029/1999JD901105

Sear CB, Kelly PM, Jones PD, Goodess CM (1987) Global surface-temperature responses to major volcanic eruptions. Nature 330:365-367. doi: 10.1038/330365a0

Sexton DMH (2001) The effect of stratospheric ozone depletion on the phase of the Antarctic Oscillation. Geophys. Res. Lett. 28:3697-3700. doi: 10.1029/2001GL013376

Sigl M, McConnell, JR, Toohey M, Plunkett G, Ludlow F, Winstrup M, Kipfstuhl S, Motizuki Y (2015a) The history of volcanic eruptions since Roman times. PAGES Mag 23:48-49. doi: 10.22498/pages.23.2.48

Sigl M, Winstrup M, McConnell JR, Welten KC, Plunkett G, Ludlow F, Büntgen U, Caffee M, Chellman N, Dahl-Jensen D, Fischer H, Kipfstuhl S, Kostick C, Maselli OJ, Mekhaldi F, Mulvaney R, Muscheler R, Pasteris DR, Pilcher JR, Salzer M, Schüpbach S, Steffensen JP, Vinther BM, Woodruff TE (2015b) Timing and climate forcing of volcanic eruptions for the past 2,500 years. Nature 523:543-549. doi: 10.1038/nature14565

Sigmond M, Reader MC, Fyfe JC, Gillett NP (2011) Drivers of past and future Southern Ocean change: Stratospheric ozone versus greenhouse gas impacts. Geophys. Res. Lett. 38:n/a-n/a. doi: $10.1029 / 2011 \mathrm{GL} 047120$

Silvestri G, Vera C (2009) Nonstationary Impacts of the Southern Annular Mode on Southern Hemisphere Climate. J. Climate 22:6142-6148. doi: 10.1175/2009JCLI3036.1

Silvestri GE, Vera CS (2003) Antarctic Oscillation signal on precipitation anomalies over southeastern South America. Geophys. Res. Lett. 30. doi: 10.1029/2003GL018277

Sinclair MR, Renwick JA, Kidson JW (1997) Low-Frequency Variability of Southern Hemisphere Sea Level Pressure and Weather System Activity. Mon. Wea. Rev. 125:2531-2543. doi: 10.1175/1520-0493(1997)125<2531:LFVOSH>2.0.CO;2

Smerdon JE, Pollack HN (2016) Reconstructing Earth's surface temperature over the past 2000 years: The science behind the headlines. WIREs Clim Change 7:746-771. doi: 10.1002/wcc.418

Son S-W, Gerber EP, Perlwitz J, Polvani LM, Gillett NP, Seo K-H, Eyring V, Shepherd TG, Waugh D, Akiyoshi H, Austin J, Baumgaertner A, Bekki S, Braesicke P, Brühl C, Butchart N, Chipperfield MP, Cugnet D, Dameris M, Dhomse S, Frith S, Garny H, Garcia R, Hardiman SC, Jöckel P, Lamarque JF, Mancini E, Marchand M, Michou M, Nakamura T, Morgenstern O, Pitari G, Plummer DA, Pyle J, Rozanov E, Scinocca JF, Shibata K, Smale D, Teyssèdre H, Tian W, Yamashita Y (2010) Impact of stratospheric ozone on Southern Hemisphere circulation change: A multimodel assessment. J. Geophys. Res. 115. doi: 10.1029/2010JD014271

Stenni B, Curran MAJ, Abram NJ, Orsi A, Goursaud S, Masson-Delmotte V, Neukom R, Goosse H, Divine D, van Ommen T, Steig EJ, Dixon DA, Thomas ER, Bertler NAN, Isaksson E, Ekaykin A, Frezzotti M, Werner M (2017) Antarctic climate variability at regional and continental scales over the last 2,000 years. Clim. Past 2017:1-35. doi: 10.5194/cp-2017-40

Sterl A, van Oldenborgh GJ, Hazeleger W, Burgers G (2007) On the robustness of ENSO teleconnections. Clim Dyn 29:469-485. doi: 10.1007/s00382-007-0251-z

Swart NC, Fyfe JC (2012) Observed and simulated changes in the Southern Hemisphere surface westerly wind-stress. Geophys. Res. Lett. 39:n/a-n/a. doi: 10.1029/2012GL052810

Taylor MH, Losch M, Wenzel M, Schröter J (2013) On the Sensitivity of Field Reconstruction and Prediction Using Empirical Orthogonal Functions Derived from Gappy Data. J. Climate 26:91949205. doi: 10.1175/JCLI-D-13-00089.1 
Thompson DWJ, Solomon S (2002) Interpretation of recent Southern Hemisphere climate change. Science 296:895-899. doi: 10.1126/science.1069270

Thompson DWJ, Wallace JM (2000) Annular Modes in the Extratropical Circulation. Part I: Month-toMonth Variability*: Journal of Climate. J. Climate 13:1000-1016. doi: 10.1175/15200442(2000)013<1000:AMITEC>2.0.CO;2

Thompson DWJ, Solomon S, Kushner PJ, England MH, Grise KM, Karoly DJ (2011) Signatures of the Antarctic ozone hole in Southern Hemisphere surface climate change. Nature Geosci 4:741-749. doi: 10.1038/ngeo1296

Toohey M, Krüger K, Niemeier U, Timmreck C (2011) The influence of eruption season on the global aerosol evolution and radiative impact of tropical volcanic eruptions. Atmos. Chem. Phys. 11:12351-12367. doi: 10.5194/acp-11-12351-2011

Tusell F (2011) Kalman Filtering in R. J. Stat. Soft. 39. doi: 10.18637/jss.v039.i02

van Oldenborgh GJ (2005) Searching for decadal variations in ENSO precipitation teleconnections. Geophys. Res. Lett. 32:1845. doi: 10.1029/2005GL023110

Vieira LEA, Solanki SK, Krivova NA, Usoskin I (2011) Evolution of the solar irradiance during the Holocene. A\&A 531:A6. doi: 10.1051/0004-6361/201015843

Villalba R, Lara A, Masiokas MH, Urrutia R, Luckman BH, Marshall GJ, Mundo IA, Christie DA, Cook ER, Neukom R, Allen K, Fenwick P, Boninsegna JA, Srur AM, Morales MS, Araneo D, Palmer JG, Cuq E, Aravena JC, Holz A, LeQuesne C (2012) Unusual Southern Hemisphere tree growth patterns induced by changes in the Southern Annular Mode. Nature Geosci 5:793-798. doi: 10.1038/ngeo1613

von Storch H, Zorita E, Jones JM, Dimitriev Y, González-Rouco F, Tett SFB (2004) Reconstructing past climate from noisy data. Science 306:679-682. doi: 10.1126/science.1096109

Wahl ER, Ammann CM (2007) Robustness of the Mann, Bradley, Hughes reconstruction of Northern Hemisphere surface temperatures: Examination of criticisms based on the nature and processing of proxy climate evidence. Climatic change 85:33-69. doi: 10.1007/s10584-006-9105-7

Wahl ER, Smerdon JE (2012) Comparative performance of paleoclimate field and index reconstructions derived from climate proxies and noise-only predictors. Geophys. Res. Lett. 39:n/a-n/a. doi: 10.1029/2012GL051086

Wahl ER, Ritson DM, Ammann CM (2006) Comment on "Reconstructing past climate from noisy data". Science 312:529; author reply 529. doi: 10.1126/science.1120866

Watterson IG (2000) Southern Midlatitude Zonal Wind Vacillation and Its Interaction with the Ocean in GCM Simulations. J. Climate 13:562-578. doi: 10.1175/15200442(2000)013<0562:SMZWVA>2.0.CO;2

Werner JP, Tingley MP (2015) Technical Note: Probabilistically constraining proxy age?depth models within a Bayesian hierarchical reconstruction model. Clim. Past 11:533-545. doi: 10.5194/cp-11533-2015 